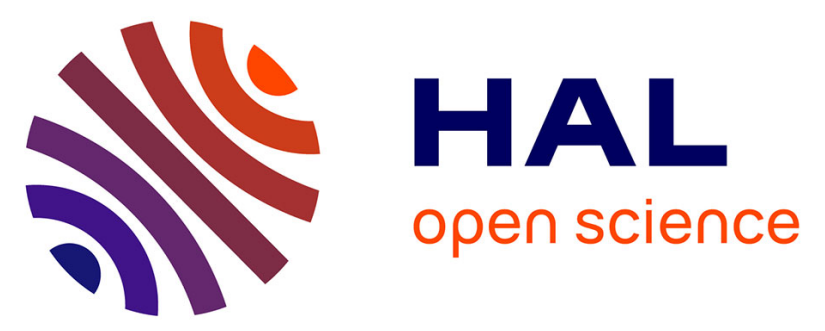

\title{
Cattle as natural host for Schistosoma haematobium (Bilharz, 1852) Weinland, $1858 \times$ Schistosoma bovis Sonsino, 1876 interactions, with new cercarial emergence and genetic patterns
}

Boris A.E.S. Savassi, Gabriel Mouahid, Chrystelle Lasica, Samoussou-Dine

Mahaman, André Garcia, David Courtin, Jean-François Allienne, Moudachirou Ibikounlé, Hélène H. Moné

\section{- To cite this version:}

Boris A.E.S. Savassi, Gabriel Mouahid, Chrystelle Lasica, Samoussou-Dine Mahaman, André Garcia, et al.. Cattle as natural host for Schistosoma haematobium (Bilharz, 1852) Weinland, $1858 \mathrm{x}$ Schistosoma bovis Sonsino, 1876 interactions, with new cercarial emergence and genetic patterns. Parasitology Research, 2020, 10.1007/s00436-020-06709-0 . hal-02733219

\author{
HAL Id: hal-02733219 \\ https://hal.science/hal-02733219
}

Submitted on 2 Dec 2020

HAL is a multi-disciplinary open access archive for the deposit and dissemination of scientific research documents, whether they are published or not. The documents may come from teaching and research institutions in France or abroad, or from public or private research centers.
L'archive ouverte pluridisciplinaire HAL, est destinée au dépôt et à la diffusion de documents scientifiques de niveau recherche, publiés ou non, émanant des établissements d'enseignement et de recherche français ou étrangers, des laboratoires publics ou privés. 
Cattle as natural host for Schistosoma haematobium (Bilharz, 1852) Weinland, $1858 x$ Schistosoma bovis Sonsino, 1876 interactions, with new cercarial emergence and genetic patterns

Boris A.E.S. Savassi, Gabriel Mouahid, Chrystelle Lasica, Samoussou-Dine K. Mahaman, André Garcia, David Courtin, Jean-François Allienne

Parasitology Research ONLINE Founded as Zeitschrift für Parasitenkunde FIRST

ISSN 0932-0113

Parasitol Res

DOI 10.1007/s00436-020-06709-0 
Your article is protected by copyright and all rights are held exclusively by SpringerVerlag GmbH Germany, part of Springer Nature. This e-offprint is for personal use only and shall not be self-archived in electronic repositories. If you wish to self-archive your article, please use the accepted manuscript version for posting on your own website. You may further deposit the accepted manuscript version in any repository, provided it is only made publicly available 12 months after official publication or later and provided acknowledgement is given to the original source of publication and a link is inserted to the published article on Springer's website. The link must be accompanied by the following text: "The final publication is available at link.springer.com". 


\title{
Cattle as natural host for Schistosoma haematobium (Bilharz, 1852) Weinland, 1858 x Schistosoma bovis Sonsino, 1876 interactions, with new cercarial emergence and genetic patterns
}

\author{
Boris A.E.S. Savassi ${ }^{1,2} \cdot$ Gabriel Mouahid $^{1}$ (D) Chrystelle Lasica $^{1} \cdot$ Samoussou-Dine K. Mahaman $^{2} \cdot$ André Garcia $^{3}$. \\ David Courtin $^{4} \cdot$ Jean-François Allienne ${ }^{1} \cdot$ Moudachirou Ibikounlé $^{2} \cdot$ Hélène Moné $^{1}$ (D)
}

Received: 16 December 2019 / Accepted: 5 May 2020

(C) Springer-Verlag GmbH Germany, part of Springer Nature 2020

\begin{abstract}
Schistosomiasis remains a parasitic infection which poses serious public health consequences around the world, particularly on the African continent where cases of introgression/hybridization between human and cattle schistosomiasis are being discovered on a more frequent basis in humans, specifically between Schistosoma haematobium and S. bovis. The aim of this paper is to analyze the occurrence of $S$. bovis in cattle and its relationship with $S$. haematobium in an area where cattle and humans share the same site in Benin (West Africa). We used the chronobiology of cercarial emergence as an ecological parameter and both molecular biology (COI mtDNA and ITS rDNA) of the larvae and morphology of the eggs as taxonomic parameters. The results showed a chronobiological polymorphism in the cercarial emergence rhythm. They showed for the first time the presence of $S$. bovis in Benin, the presence of introgressive hybridization between $S$. bovis and S. haematobium in domestic cattle, and the presence of atypical chronobiological patterns in schistosomes from cattle, with typical S. haematobium shedding pattern, double-peak patterns, and nocturnal patterns. Our results showed that the chronobiological life-history trait is useful for the detection of new hosts and also may reveal the possible presence of introgressive hybridization in schistosomes. Our results, for the first time, place cattle as reservoir host for $S$. haematobium and S. bovis $x$ S. haematobium. The consequences of these results on the epidemiology of the disease, the transmission to humans, and the control of the disease are very important.
\end{abstract}

Keywords Schistosoma bovis · Schistosoma haematobium · Introgressive hybridization · Cercarial emergence pattern · Cattle · Benin

\section{Introduction}

Schistosomiasis or Bilharziasis remains a parasitic infection which poses serious public health consequences around the

Section Editor: Hiroshi Sato

Hélène Moné

mone@univ-perp.fr

1 University of Perpignan Via Domitia, IHPE UMR 5244, CNRS, IFREMER, University of Montpellier, 58 avenue Paul Alduy, Bât. R, F-66860 Perpignan, France

2 Faculté des Sciences et Techniques, Université d'Abomey-Calavi, 01BP526 Cotonou, Benin

3 UMR 261 MERIT, Institut de Recherche pour le Développement (IRD), Cotonou, Bénin

4 UMR 261 MERIT, Institut de Recherche pour le Développement (IRD), Université de Paris, Paris, France world, particularly on the African continent which harbors $85 \%$ of the total number of infected people worldwide (Chitsulo et al. 2000; Engels et al. 2002). In Africa, humans can be infected with four species of Schistosoma: Schistosoma mansoni Sambon, 1907, S. haematobium, S. intercalatum Fisher, 1934 and S. guineensis Pagès, Jourdane, Southgate \& Tchuem Tchuenté, 2003 where $S$. haematobium is the most prevalent species affecting around 112 million people (WHO 2019). Cattle schistosomiasis affects approximately 165 million domestic cattle worldwide and the disease is of veterinary and economic significances (De Bont and Vercruysse 1997). In Africa, species such as $S$. bovis, S. curassoni Brumpt, 1931, S. mattheei Veglia \& Le Roux 1929, and S. leiperi Le Roux, 1955 are responsible for inducing severe infections in animals (De Bont and Vercruysse 1998). Africa is also the continent where cases of introgression/hybridization between human and cattle schistosomes are being discovered on a more frequent basis, specifically between S. haematobium and 
S. bovis. All but one of these cases were found in humans in West Africa: in Niger (introgression of S. haematobium by genes of S. bovis, Brémond et al. 1993; Leger et al. 2016), in Senegal (bidirectional introgression, Huyse et al. 2009; Webster et al. 2013), in Mali (hybrids, Soentjens et al. 2016), in Côte d'Ivoire (Angora et al. 2019), and in Benin (introgressive hybridization, Moné et al. 2015). The outlying case was from Corsica (France) (introgressive hybridization, Moné et al. 2015). Hybridization between S. haematobium and $S$. bovis in a non-human host was found in one rodent, Mastomys huberti Wroughton, 1909 in Senegal, which was shown to harbor a hybrid female (Catalano et al. 2018).

In Benin, two species of human schistosomes are reported in the literature: S. haematobium and S. mansoni (Moné et al. 2010): S. haematobium is widely distributed, with a national prevalence of $17.6 \%$, while $S$. mansoni has a narrow distribution, with a prevalence of $2.5 \%$ (Onzo-Aboki et al. 2019). Introgressive hybridization between $S$. bovis and $S$. haematobium was already reported for humans in Benin (Moné et al. 2015) but, as a species, S. bovis was never reported in this country. This is interesting given that all of Benin's neighboring countries including Togo, Burkina Faso, Niger, and Nigeria were known to harbor this bovine species (Moné et al. 1999). In many villages in Benin, humans and cattle live in close proximity. Since the snails from the genus Bulinus are known to act as intermediate hosts for both $S$. haematobium and $S$. bovis, a logical question to consider is whether cattle in these areas could be infected by $S$. bovis or S. haematobium and if introgressive hybridization exists between the two species.

The aim of this paper is to analyze the occurrence of $S$. bovis in cattle and its relationship with $S$. haematobium in an area where cattle and humans share the same site (Fig. 1). We used the chronobiology of cercarial emergence as an ecological parameter, as the cercarial emission is related to the definitive host behavior (Théron et al. 1997; Ibikounlé et al. 2012; Mouahid et al. 2012; Mintsa-Nguema et al. 2014), the emission pattern of $S$. bovis cercariae is different (early diurnal, Mouahid et al. 1991) from that of S. haematobium cercariae (midday to late diurnal, Mouahid et al. 1991), and since schistosome cercarial emission has been shown to have a genetic base (Théron and Combes 1988). We also used both molecular biology (cytochrome $c$ oxidase (COI mtDNA) and internal transcribed spacer (ITS rDNA)) of the larvae and morphology of the eggs as taxonomic parameters.

\section{Materials and methods}

\section{Geographical sampling position}

The study was conducted on cows and schoolchildren (elementary school; latitude N: 6³4'39.84"; longitude E: $2^{\circ} 31^{\prime}$
9.03") from 2017 to 2018 in Kessounou Village, located in the department of Ouémé in southeastern Benin (Fig. 2). The district of Kessounou is a fluvio-lacustrine zone characterized by a four-season subequatorial climate (Abou et al. 2018): (i) a long rainy season from March to June, (ii) a short dry season in July and August, (iii) a short rainy season in September and October, and finally (iv) a long dry season that runs from November to February. The Ouémé River crosses Kessounou and periodically floods the entire area during its flood period (mid-July to early November). During the period where river water levels are low (December to June), almost all of the water disappears giving way to ponds in various places. The climatic characteristics observed at Kessounou favor the seasonal installation of freshwater snails, especially during the flood period. Adults engage in fishing, agriculture, and livestock breeding. Schoolchildren regularly fish and search for crabs and shrimps for sale, which places them in permanent contact with contaminated waters. Cattle breeding is done in collectivity. Cows are left to wander even during periods of flooding and they never leave Kessounou unless they are sold. According to the breeders, most of the cows were born in Kessounou and some have spent more than 20 years in the one location.

\section{Schistosoma egg and miracidium recoveries from cattle}

The feces from 48 cows were collected individually (from 150 to $250 \mathrm{~g}$ ), immediately after defecation. The infection status of each fecal sample was analyzed using the miracidial hatching test from $50 \mathrm{~g}$ of feces. The filtration technique consisted of placing the $50 \mathrm{~g}$ of feces in a container with half a liter of $\mathrm{NaCl}$ $9 \%$ o saline solution. The solution was then homogenized using an electric hand mixer, passed through a series of decreasing mesh vacuum sieves $(315 \mu \mathrm{m}, 180 \mu \mathrm{m}, 106 \mu \mathrm{m}$, and $45 \mu \mathrm{m})$, then washed with $\mathrm{NaCl} 9 \%$ o saline solution using a pressure pump. The residues retained on the $45 \mu \mathrm{m}$ pore size sieve were placed in a beaker containing drilling water, at room temperature under light, for miracidial hatching. Among the 48 cows, 35 were found positive $(73 \%)$. We chose to continue the analyses with the four fecal samples that gave the most miracidia (BK19, BK24, BK26, and BK29). The rest of the fecal sample from each of the four cows was then filtered as above and separated into two subsamples: the first subsample was once again passed through the $45 \mu \mathrm{m}$ pore size sieve, and the eggs were placed in a beaker containing drilling water for miracidial hatching. Several miracidia from each cow were collected individually onto FTA® Classic Cards (Whatman, GE Healthcare companies, Little Chalfont, United Kingdom) and then transferred to University of Perpignan (France) for molecular analyses; the rest of the miracidia from the four cows were mixed and used for snail infection; the second subsamples from the four cows were once again individually 
Fig. 1 Kessounou sampling area where cows access water in close proximity to houses

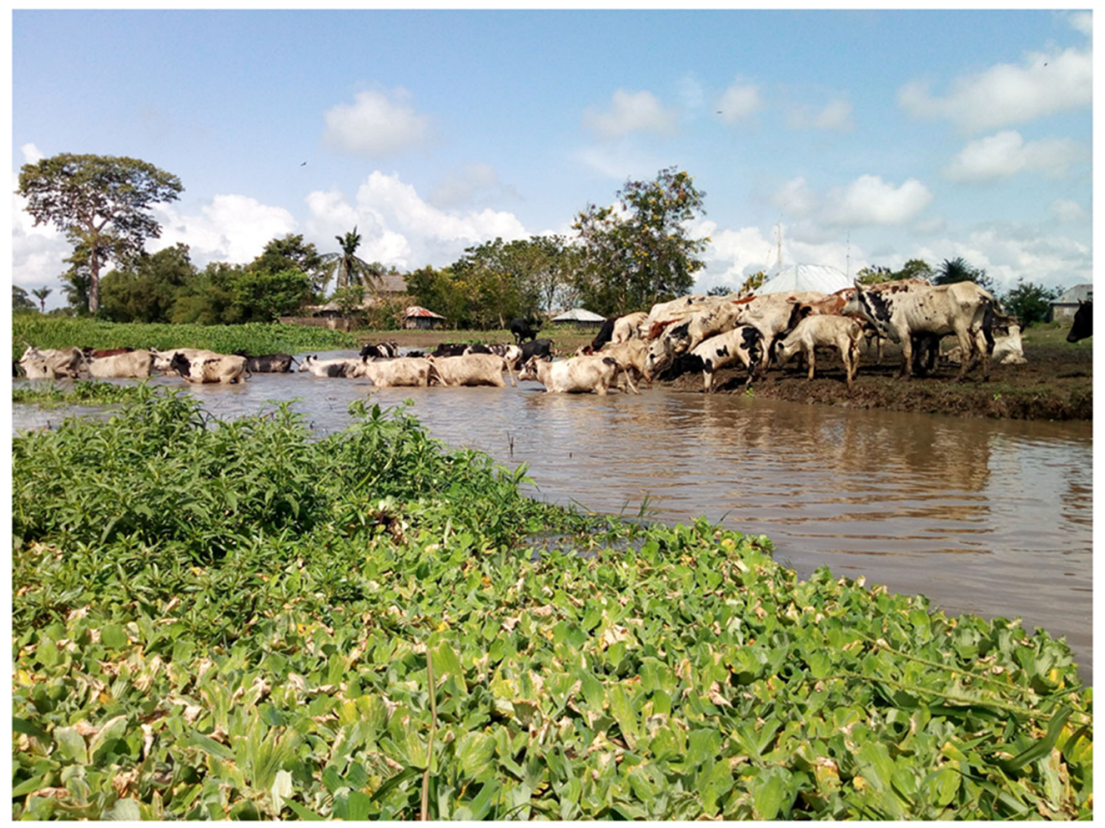

passed through the $45 \mu \mathrm{m}$ pore size sieve in $9 \%$ NaCl saline solution and the eggs from the four subsamples were mixed for an egg morphology study.

\section{Schistosoma egg and miracidium recoveries from schoolchildren}

Urine samples from 76 schoolchildren were collected individually. The infection status of each urine sample was analyzed using the syringe filtration technique (Boko et al. 2016; Onzo-Aboki et al. 2019) after staining each filter with Lugol solution. One of the 18 girls' samples (5.6\%) and 4 of the 58 boys $(6.9 \%)$ were found positive. The rest of the five positive urine-egg samples (DK20, DK23, DK54, KE14, and KE15) were individually filtered according to the same procedure as above, and the filters were placed in saline solution. Two subsamples were made from each urine sample: the first subsample was passed through a $45 \mu \mathrm{m}$ pore size sieve and the eggs were placed in a beaker containing drilling water for miracidial hatching. Several miracidia were collected individually for each urine sample in Eppendorf tubes (only one miracidium per tube), containing $95^{\circ}$ alcohol, then transferred to the University of Perpignan (France) for molecular analyses. The second subsamples from the five urine samples were mixed in saline solution for an egg morphology study.
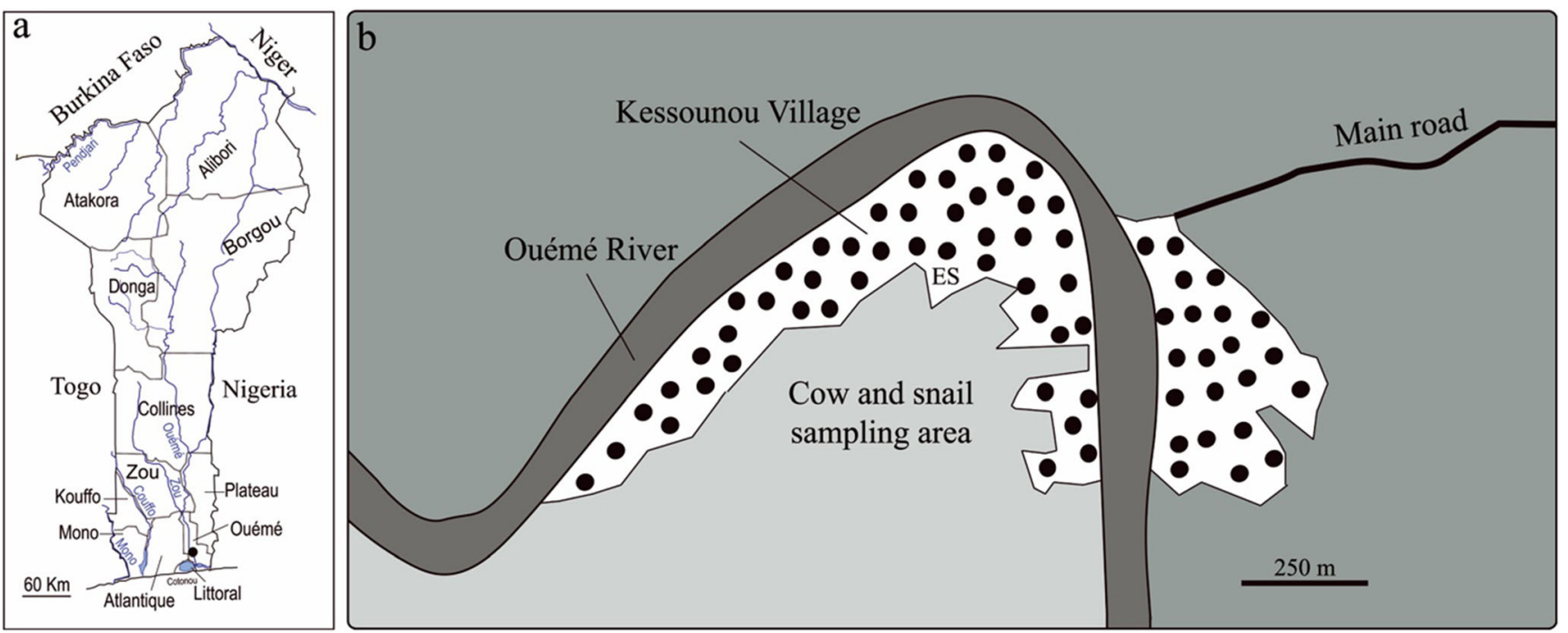

Fig. 2 Sampling area. a Map of Benin; Kessounou Village (black circle) in Ouémé Department. b Kessounou Village (white with black circles). ES: Elementary School 
The stools from the four urine-egg-positive boys were collected individually. Each stool was passed through a series of sieves $(315,180,106$, and 45 pore size) and washed through with $9 \%$ NaCl saline solution with a pressure pump.

The eggs that were retained on the $45 \mu \mathrm{m}$ pore size sieve were collected in a beaker containing saline solution. The presence of eggs was ascertained under a binocular microscope. Only one stool was found positive and two subsamples were made: the first subsample was passed through the $45 \mu \mathrm{m}$ pore size sieve and the eggs were placed in a beaker containing drilling water for miracidial hatching. Several miracidia were collected individually in Eppendorf tubes (only one miracidium per tube) containing $95^{\circ}$ alcohol, then transferred to the University of Perpignan (France) for molecular analyses. The second subsample was kept in $9 \%$ o $\mathrm{NaCl}$ saline solution for an egg morphology study.

\section{Snail infection}

Two species of freshwater snails, Bulinus forskalii (Ehrenberg, 1831) and Bulinus globosus (Morelet, 1866), were collected in Kessounou Village and used in this study. These species were identified using shell morphology (Brown 1994). All of the collected snails were tested for infection with schistosomes or other trematodes for a period of 55 days. None of the snails used for the infection were found to be naturally infected. We exposed 43 Bulinus forskalii (6.3 to $8.2 \mathrm{~mm}$ in height) and 62 Bulinus globosus (4.4 to $7.6 \mathrm{~mm}$ in height), individually, to 3 miracidia obtained from the eggs originating from a mixture of feces from the 4 cows (BK19, BK24, BK26, and BK29). The snails of each species were maintained separately, fed with dry and fresh salad in water at $28{ }^{\circ} \mathrm{C}$ with a balanced photoperiod ( $12 \mathrm{~h}$ light, $12 \mathrm{~h}$ dark) and a photophase from 6:00 am to 6:00 pm. The snails were then transferred to Perpignan (France) for cercarial emission and molecular analyses.

\section{Cercarial emergence pattern}

The snails were maintained individually in glass vessels containing $150 \mathrm{ml}$ of drilling water, at a constant temperature $\left(25{ }^{\circ} \mathrm{C}\right)$, balanced photoperiod (light/dark: $\left.12 \mathrm{~h} / 12 \mathrm{~h}\right)$, and photophase (6:00 am to 6:00 pm). They were given fresh washed lettuce ad libitum. The cercarial emission rhythm (chronobiology) was studied for five consecutive days for 13 infected snails, 11 Bulinus forskalii (Kf1 to Kf11), and 2 Bulinus globosus ( $\mathrm{Kg} 1$ and $\mathrm{Kg} 2$ ) to show the stability of the emission pattern, from the 6th day after the first day of the patent period, i.e., 32 to 38 days after snail exposure to the miracidia. Each hour, each snail, with its lettuce, was transferred into a new vessel. The water left in the vessel, containing the cercariae, was transferred to a container where a few drops of Lugol solution was added to kill the cercariae and red-color them; this solution was then filtered through a Nitrel polyamide filter $(25 \mu \mathrm{m}$ pore size). The cercariae retained on the filter were counted under the binocular microscope.

Cercariae emitted by four infected Bulinus forskalii (Kf5, $\mathrm{Kf6}, \mathrm{Kf} 8$, and Kf9) and the two Bulinus globosus (Kg1 and $\mathrm{Kg} 2$ ) were individually stored onto FTA ${ }^{\circledR}$ Classic Cards (Whatman, GE Healthcare companies, Little Chalfont, United Kingdom), as described above, for molecular studies.

\section{Molecular analyses}

\section{DNA extraction}

DNA from miracidia collected in alcohol was extracted according Beltran et al. (2008) and stored at $-20^{\circ} \mathrm{C}$. DNA from either miracidia or cercariae individually stored on FTA ${ }^{\circledR}$ Classic Cards (Whatman, GE Healthcare companies, Little Chalfont, United Kingdom) was extracted as follows. A 3mm disk was removed with a Craft Punch from the FTA ${ }^{\circledR}$ Classic Cards at the center of where the miracidium or cercaria was loaded. The disks were deposited in Eppendorf tubes $(1.5 \mathrm{ml})$ and an initial washing step with $100 \mu \mathrm{l}$ of Milli-Q water was performed. After a $10-\mathrm{mn}$ incubation at room temperature, water was removed and replaced with $80 \mu \mathrm{l}$ of $5 \%$ Chelex® 100 Molecular Biology Grade Resin solution (BioRad Laboratories, Hercules, California, USA). The sample was then heated to $65^{\circ} \mathrm{C}$ for $30 \mathrm{~min}$ at a stirring speed of $800 \mathrm{rpm}$ followed by a second heating at $99{ }^{\circ} \mathrm{C}$ for $8 \mathrm{~min}$ without stirring. DNA was finally collected by centrifugation at $14,000 \mathrm{rpm}$ for $2 \mathrm{~min}$. Fifty microliters of the supernatant (DNA) of each sample was taken and stored at $-20{ }^{\circ} \mathrm{C}$ for further molecular analyses.

\section{Rapid diagnostic multiplex PCR}

A rapid diagnostic multiplex PCR was used to target the COI mtDNA gene. We used the technique of Webster et al. (2010), optimized by Van den Broeck et al. (2011) and Angora et al. (2019). The primers were one universal reverse primer (Shmb.R: 5'-CAA GTA TCA TGA AAY ART ATR TCT AA-3') and three species-specific forward primers (for S. haematobium (120 bp) Sh.F: 5'-GGT CTC GTG TAT GAG ATC CTA TAG TTT G-3', for S. bovis (260 bp) Sb.F: 5'-GTT TAG GTA GTG TAG TTT GGG CTC AC-3' and for S. mansoni (215 bp) Sm.F: 5'-CTT TGA TTC GTT AAC TGG AGT G-3'). Each PCR amplification of partial COI mtDNA was carried out in a total volume of $10 \mu \mathrm{l}$, containing $2 \mu \mathrm{l}$ of DNA template, $2 \mu \mathrm{l}$ of the GoTaq ${ }^{\circledR}$ Flexy buffer (Promega; Madison, Wisconsin, USA), $0.6 \mu$ of $25 \mathrm{mM}$ $\mathrm{MgCl}_{2}, 1 \mu \mathrm{l}$ of $10 \times$ primer mix $(4 \mu \mathrm{l}$ of $100 \mu \mathrm{M}$ universal reverse primer, $4 \mu \mathrm{l}$ of each $100 \mu \mathrm{M}$ forward primer, and $84 \mu \mathrm{l}$ of milli-Q water), $0.2 \mu \mathrm{l}$ solutions of dNTP at $10 \mathrm{mM}$ each, $0.2 \mu$ of the GoTaq ${ }^{\circledR}$ G2 Hot Start Taq Polymerase 
(Promega), and $4 \mu \mathrm{l}$ milli-Q water. The PCR conditions involved an initial phase of activation of GoTaq Polymerase at $95^{\circ} \mathrm{C}$ for 3 min followed by 45 amplification cycles. Each cycle comprised DNA denaturation step at $95{ }^{\circ} \mathrm{C}$ for $10 \mathrm{~s}$, followed by primer annealing at $52{ }^{\circ} \mathrm{C}$ for $30 \mathrm{~s}$, and an elongation step at $72{ }^{\circ} \mathrm{C}$ for $10 \mathrm{~s}$. The program ended with a final extension at $72{ }^{\circ} \mathrm{C}$ for $2 \mathrm{~min}$. The PCR products were examined on $2.5 \%$ agarose gels at $135 \mathrm{~V}$ for $40 \mathrm{~min}$ using the 100 bp DNA size marker (Promega) for size estimation.

\section{COI mtDNA PCR}

Partial COI mtDNA amplification was performed by PCR using the forward primer, Cox1_schist F: 5'-TCTT TRGATCATAAGCG-3', and the reverse primer, Cox1_schist-R: 5'-TAATGCATMGGAAAAAAACA-3' (Lockyer et al. 2003). PCR conditions used were those as described in Moné et al. (2015).

\section{ITS rDNA PCR}

PCR amplification of ITS rDNA (partial 18S, ITS1, 5.8S, and ITS2) was performed using the primers of Barber et al. (2000): ITS4F: 5'-TCCTCCGCTTATTGATATGC-3'; ITS5R: 5'GGAAGTAAAAGTCGTAACAAGG-3'. The amplification was carried out in a total reaction volume of $25 \mu$, containing $2 \mu \mathrm{l}$ of DNA; $1.5 \mu \mathrm{l}$ of $\mathrm{MgCl}_{2}(25 \mathrm{mM}), 5 \mu \mathrm{l}$ of the $5 \times$ buffer (Promega), $1 \mu \mathrm{l}$ of each of the primers $(10 \mu \mathrm{M}), 0.5 \mu \mathrm{l}$ of each dNTP $(10 \mathrm{mM}), 0.2 \mu \mathrm{l}$ of Go Taq polymerase (Promega), and $13.8 \mu \mathrm{l}$ of $\mathrm{H} 2 \mathrm{O}$ using a thermocycler (Techne TC-Plus, Bibby Scientific, Staffordshire, UK). The reaction conditions included an activation step at $95{ }^{\circ} \mathrm{C}$ for $3 \mathrm{~min}$, followed by 45 amplification cycles. Each cycle comprised a DNA denaturation step at $95^{\circ} \mathrm{C}$ for $40 \mathrm{~s}$, followed by primer annealing at $48{ }^{\circ} \mathrm{C}$ for $40 \mathrm{~s}$ and an elongation step at $72{ }^{\circ} \mathrm{C}$ for $1 \mathrm{~min} 10 \mathrm{~s}$ and a final extension at $72{ }^{\circ} \mathrm{C}$ for $5 \mathrm{~min}$. One percent agarose gel electrophoresis was used to visualize the ITS rDNA-PCR products.

\section{Sequencing}

Partial COI mtDNA gene and ITS rDNA region were sequenced (Genoscreen; Lille, France) using the reverse primers; some regions were also sequenced using the forward primer in order to confirm the sequence. The sequences were manually edited using Sequencher 4.5 (Gene Codes Corporation, Ann Arbor, USA). For the analysis of nuclear gene sequences (ITS rDNA), the sequence polymorphism was verified and confirmed by visualization of the raw sequence chromatograms. Since this gene has biparental transmission and segregation sites (polymorphic sites) between $S$. haematobium and $S$. bovis, the sequence chromatograms were carefully checked to identify the presence of possible heterozygosity. At each polymorphic site where two chromatogram peaks overlapped (indicating the genetic signature of both parents), the IUPAC ambiguity symbols were used to indicate the individual nucleotide polymorphisms. Thus, Y indicates the presence of the bases $\mathrm{T}$ and $\mathrm{C}$, rather than an ambiguous reading between $\mathrm{T}$ and $\mathrm{C}$. Similarly, $\mathrm{R}$ indicates the presence of the bases $A$ and $G$ and not an ambiguous reading between $\mathrm{A}$ and $\mathrm{G}$. The different haplotypes and the different profiles are presented in Table 1 for the COI mtDNA gene and the ITS rDNA region, respectively.

\section{Partial COI mtDNA phylogenetic analysis}

DNA multiple sequence alignments were performed using Muscle program (Edgar 2004) on the MEGA 7.0 software (Kumar et al. 2016) and refined by Gblocks $0.91 \mathrm{~b}$ (Castresana 2000; Dereeper et al. 2008, 2010). The probabilistic model of sequence evolution (Nei and Kumar 2000) and the gamma distribution $(\mathrm{G})$ to approximate rate heterogeneity among haplotypes was performed using MEGA 7.0 software. The best model with the lowest BIC score (Bayesian Information Criterion) was HKY + G (Hasegawa-KishinoYano with the gamma distribution). A phylogenetic tree using the maximum likelihood method was constructed. The maximum likelihood method was performed using MEGA 7.0 software. Reliability for internal branch was assessed using bootstrapping procedure (1000 replicates). The topology of the tree was rooted by $S$. intercalatum. The comparison was also performed using the percentage of difference calculated from the pairwise distances data obtained by using MEGA 7.0 software.

\section{Egg morphology}

The eggs were mounted individually at random in a $9 \% \circ \mathrm{NaCl}$ solution beneath glass cover-slips on glass slides using a Pasteur pipette. They were photographed and measured (length, width, spine length, and length/width ratio) by microscopy. Only the eggs which contained a living miracidium were measured. In total, 113 eggs were measured: 47 from cow feces, 48 from schoolchildren urines, and 18 from the schoolchildren stool.

\section{Statistical analyses}

Means and standard errors were calculated. The MannWhitney test was used for measure comparisons and the Fisher's exact test was used for proportion comparisons using the BiostaTGV https://biostatgv.sentiweb.fr. The probability values $(p)$ less than $5 \%$ were considered statistically significant. 
Table 1 Origin and sample label of the miracidia and cercariae used for the molecular analyses. Number of haplotypes/number of sequenced larval stages (either miracidia or cercariae) for the COI mtDNA gene and number of profiles/number of sequenced larval stages (either miracidia or cercariae) for the ITS rDNA region

\begin{tabular}{llll}
\hline Host_Biological material_Larval stage & Sample label & COI mtDNA & ITS rDNA \\
\hline Cow_feces_miracidium & BK19 & $3 / 5$ & $2 / 5$ \\
& BK24 & $2 / 5$ & $3 / 5$ \\
& BK26 & $2 / 5$ & $3 / 5$ \\
B. forskalii exposed to miracidia from cows_Cercaria & BK29 & $3 / 5$ & $2 / 5$ \\
& Kf5 & $1 / 5$ & $1 / 5$ \\
& Kf6 & $1 / 3$ & $1 / 3$ \\
& Kf8 & $1 / 3$ & $1 / 3$ \\
B. globosus exposed to miracidia from cows_Cercaria & Kf9 & $2 / 3$ & $1 / 3$ \\
& Kg1 & $1 / 5$ & $1 / 5$ \\
Child_urine_miracidium & Kg2 & $1 / 5$ & $1 / 5$ \\
& DK20 & $1 / 3$ & - \\
& DK23 & $4 / 6$ & $5 / 6$ \\
& DK54 & $2 / 2$ & $1 / 2$ \\
Child_stool_miracidium & KE14 & $2 / 11$ & $6 / 14$ \\
\end{tabular}

BK, Kf, and Kg: cow origin; DK and KE: schoolchild origin; “-”: not available

\section{Results}

\section{Snail infection}

Of the 43 B. forskalii that were exposed, 16 survived and 11 shed cercariae $(69 \%)$ ( Kfl to $\mathrm{Kf} 11)$; of the 62 B. globosus that were exposed, 52 survived and only 2 shed cercariae $(2.9 \%)$ ( $\mathrm{Kg} 1$ and $\mathrm{Kg} 2$ ). The percentage of infection was significantly higher for $B$. forskalii compared to B. globosus (Fisher's exact test; $p<0.0001$ ). Prepatent periods lasted 26 days (from the $B$. forskalii $\mathrm{Kf1}, \mathrm{Kf} 2, \mathrm{Kf} 3, \mathrm{Kf} 4, \mathrm{Kf5}, \mathrm{Kf} 6, \mathrm{Kf} 7$, and $\mathrm{Kf} 8$ and from the B. globosus $\mathrm{Kg} 1$ ), 30 days (from the B. forskalii Kf9 and $\mathrm{Kf10}$ ), or 32 days (from the B. forskalii Kf11 and from the B. globosus $\mathrm{Kg} 2$ ).

\section{Cercarial emission patterns}

The cercarial emission patterns were analyzed for the 13 positive snails (11 B. forskalii and 2 B. globosus) during 5 consecutive days (65 occurrences in total) from the 6 th day after the first day of the patent period, i.e. 32 to 38 days after snail exposure to the miracidia. The results showed a variability in the patterns; we identified four different patterns (Fig. 3), and each snail harbored only one pattern.

a- An early diurnal pattern was observed for 7 of the 13 snails $(53.8 \%)$. Cercarial emission began at 6 am, immediately after the start of the light period; it increased very rapidly to reach an emission peak at either 7 am (for Kf1 and $\mathrm{Kf1} 1$ ) or 8 am (for Kf2, Kf3, Kf6, Kf7, and Kf8), then decreased gradually to stop at $2 \mathrm{pm}$. Immediately after the beginning of the dark period, very low cercarial emissions were observed at $7 \mathrm{pm}$, and sometimes at $8 \mathrm{pm}$ as well. The mean pattern showed that more than $97 \%$ of the cercariae were shed during the day and a peak occurred at 8 am (Fig. 3a);

b- A midday to late diurnal pattern was found for 1 of the 13 snails $(7.7 \%)$. More than $90 \%$ of the cercariae were shed during the day. Cercarial emission mainly occurred from 12 am to $6 \mathrm{pm}$ with an emission peak at $2 \mathrm{pm}(\mathrm{Kg} 2)$, followed by a gradual decrease during the daylight hours and then a rapid decrease at the beginning of the dark period (Fig. 3b);

c- An early diurnal and nocturnal pattern was found for 4 of the 13 snails $(30.8 \%)$. The percentages of cercariae shed during the day were highly variable and represented from more than $90 \%$ (as for the two previous chronotypes) to less than $60 \%$. The diurnal cercarial emission occurred during the 4 to 5 first hours of light with peaks at 7 am (for Kf5), 8 am (for Kf4 and Kf9), or 9 am (for Kf10). The nocturnal cercarial emission occurred mainly during the first hour of darkness where another peak was observed for the 4 snails for which Kf5 represented more than $40 \%$ of the total cercarial daily emission. The mean pattern had more than $79 \%$ of the cercariae that were shed during the day and harbored two peaks, an early peak at 8 am and a nocturnal peak at 7 pm (Fig. 3c);

d- A late diurnal and nocturnal pattern for 1 of the 13 snails $(7.7 \%)$. Roughly $60 \%$ of the cercariae were shed during 


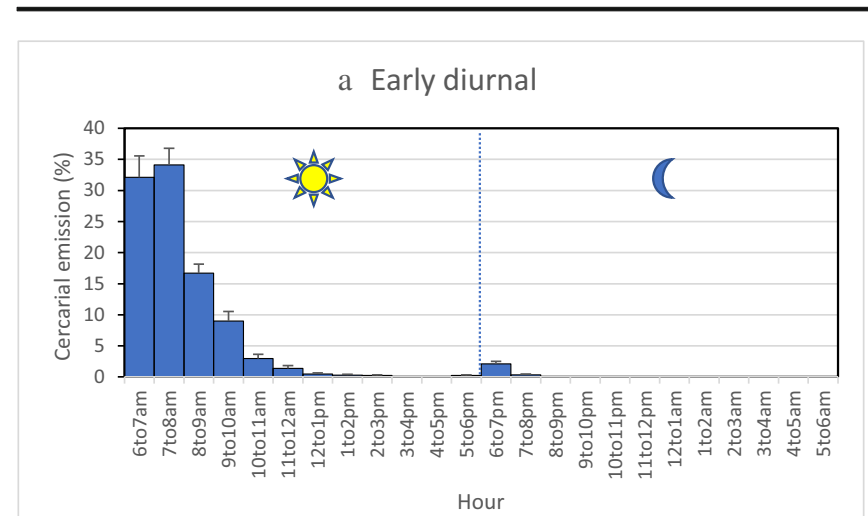

c Early diurnal and nocturnal

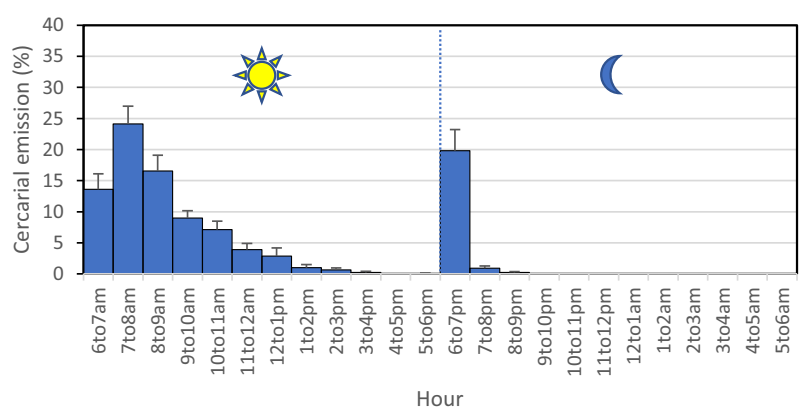

Fig. 3 Cercarial emission patterns from infected snails, each exposed to 3 miracidia of Schistosoma from cow feces. a Early diurnal pattern for B. forskalii (Kf1, Kf2, Kf3, Kf6, Kf7, Kf8 and Kf11). b Midday to late

the day. Cercarial emission occurred mainly from $4 \mathrm{pm}$ to 7 pm with an emission peak at 7 pm (Kg1) (Fig. 3d).

\section{COI mtDNA (894 bp)}

Ninety-one sequences were analyzed. The numbers of haplotypes on the numbers of sequenced larval stages for each sample ( 4 cows, 6 snails, and 5 schoolchildren) are presented in Table 1. We found from 2 to 3 haplotypes per cow, from 1 to 2 haplotypes per snail, and from 1 to 4 haplotypes per child. In total, 13 haplotypes were found: 6 haplotypes from cows (K_Cow_Hap1 to K_Cow_Hap6) which contained 13 mutation sites, all different from the 7 haplotypes from schoolchildren (K_Child_Hap7 to K_Child_Hap13), containing 16 mutation sites (Table 2). Sequence data were deposited in the NCBI GenBank database under the accession numbers MT159589 to MT159601. The percentages of differences ranged between 0.11 and $1.36 \%$ between the cow and the human haplotypes. Site polymorphism was shared between cows and schoolchildren in seven different positions while six positions were polymorph only in cows and only eight in schoolchildren. One haplotype was harbored by only one individual (either cow (K_Cow_Hap1: accession number MT159589, K_Cow_Hap2: accession number MT159590 b Midday to late diurnal

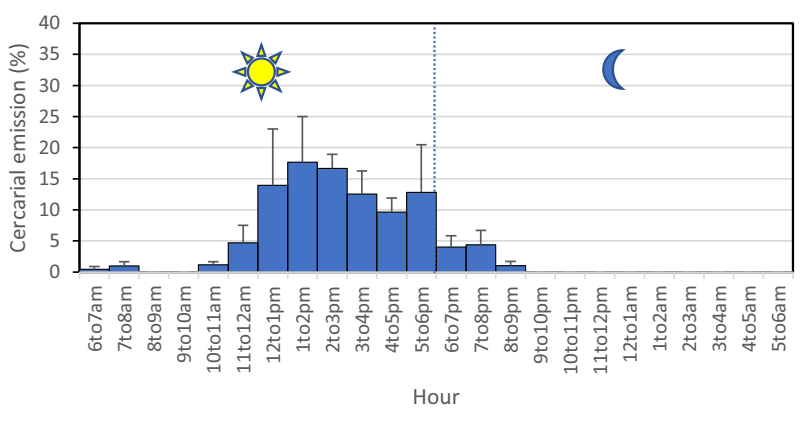

d Late diurnal and nocturnal

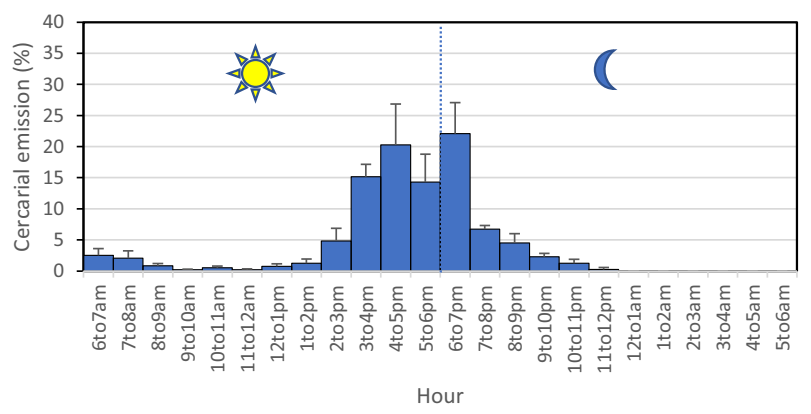

diurnal pattern for B. globosus $(\mathrm{Kg} 2)$. c Early diurnal and nocturnal pattern for B. forskalii (Kf4, Kf5, Kf9, Kf10). d Late diurnal and nocturnal pattern for B. globosus $(\mathrm{Kg} 1)$

and K_Cow_Hap6: accession number MT159594) or schoolchild (K_Child_Hap10: accession number MT159598, K_Child_Hap 12: accession number MT159600 and K_Child_Hap13: accession number MT159601)) or was shared by different cows (K_Cow_Hap3: accession number MT159591, K_Cow_Hap4: accession number MT159592 and K_Cow_Hap5: accession number MT159593) or different schoolchildren (K_Child_Hap7: accession number MT159595, K_Child_Hap8: accession number MT159596, K_Child_Hap9: accession number MT159597 and K_Child_Hap11: accession number MT159599). Three different haplotypes were found from the snails among the six recovered in the cows; they were different between B. forskalii (K_Cow_Hap1: accession number MT159589 and K_Cow_Hap2: accession number MT159590) and B. globosus (K_Cow_Hap4: accession number MT159592). Two haplotypes (K_Child_Hap8: accession number MT159596 and K_Child_Hap9: accession number MT159597) were shared by miracidia that came from the same child in both the urine and the stool.

\section{ITS rDNA (946 bp)}

Eighty-nine sequences were analyzed for the 18S, ITS1, 5.8S and ITS2 genes. The first $22 \mathrm{bp}$ of our ITS rDNA sequences belonged to the $18 \mathrm{~S}$ gene and no variability was found 


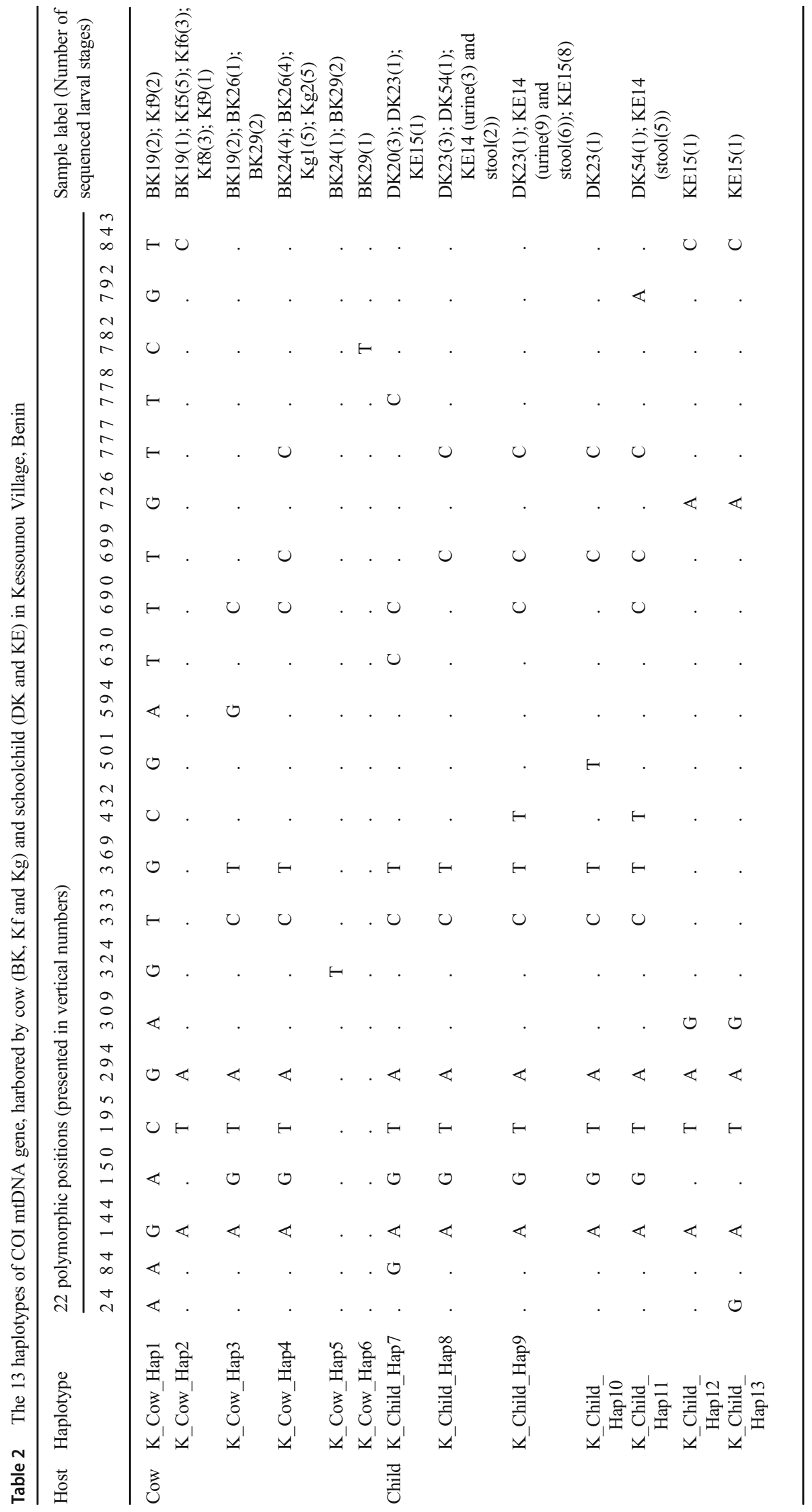


between any of our samples. We thus no longer gave this gene further consideration. Eleven profiles were found with the ITS1, 5.8S and ITS2 sequences, with 2 to 3 profiles per cow, only 1 profile per snail and 1 to 7 profiles per child (Table 1). Sequence data were deposited in the NCBI GenBank database under the accession numbers MT158872 to MT158882.

Table 3 shows that the 11 profiles may differ by their ITS1 gene (458 bp: from position 23 to position 480), with 5 genetic variants at three positions (TGT, TAT, TGY, TRT, and YAT), by their 5.8S gene (155 bp: from position 481 to position 635 ), with 2 genetic variants at 1 position ( $\mathrm{C}$ and $\mathrm{Y}$ ), and by their ITS2 gene (311 bp: from position 636 to position 946), with 3 genetic variants at 4 positions (ATAT, GCGC and RYRY). Among these 11 profiles, 1 profile corresponding to $S$. bovis ITS rDNA was found only in cows (profile 1: accession number MT158872), and 1 profile corresponding to $S$. haematobium ITS rDNA was found only in schoolchildren (profile 2: accession number MT158873). All of the other 9 profiles showed atypical sequences in ITS rDNA. Two were found only in cows (profiles 3: accession number MT158874 and 4: accession number MT158875) and showed double peaks in the ITS 1 gene. Five were found only in schoolchildren (profiles 5: accession number MT158876, 6: accession number MT158877, 7: accession number MT158878, 8: accession number MT158879 and 9: accession number MT158880) and showed double peaks in 1 or 2 of the ITS1, 5.8S and ITS2 genes. Two were found both in cows and schoolchildren, where the first one showed a typical $S$. haematobium ITS1 marker together with a typical $S$. bovis ITS2 marker (profile 10: accession number MT158881) and the second showed a typical ITS1 S. haematobium marker together with double peaks in both the 5.8S and ITS2 genes (profile 11: accession number MT158882).

\section{COI mtDNA phylogeny (881 bp)}

The 13 haplotypes obtained from the COI mtDNA sequences (haplotype code/COI mtDNA accession No: K_Cow_Hap1/ MT159589, K_Cow_Hap2/MT159590, K_Cow_Hap3/ MT159591, K_Cow_Hap4/MT159592, K_Cow_Hap5/ MT159593, K_Cow_Hap6/MT159594, K_Child_Hap7/ MT159595, K_Child_Hap8/MT159596, K_Child_Hap9/ MT159597, K_Child_Hap10/MT159598, K_Child_Hap11/ MT159599, K_Child_Hap12/MT159600, K_Child_Hap13/ MT159601) were compared to 23 published nucleotide sequences of Schistosoma (12 sequences from S. haematobium (haplotype code/COI mtDNA accession No: Sh_Gambia/ JQ397349; Sh_Liberia/JQ397350; Sh_Mali/AY157209; Sh_Egypt/JQ397368; Sh_Guinea Bissau/JQ397351; Sh_Toho_Benin/KT354661; Sh_Cameroon/JQ397365; Sh_Melen_Gabon/KT354660; Sh_Ekouk_Gabon/KT354659; Sh_Kenya/JQ397378; Sh_South Africa/JQ397397; Sh_Madagascar/JQ397399), 7 from S. bovis (haplotype code/ CÖI mtDNA accession No: SbxSh_Corsical_France/ KT354656; SbxSh_Corsica2_France/KT354657; SbxSh_Corsica3_France/KT354658; SbxSh_SôTchanhoué_Benin/KT354662; Sb_Senegal/AJ519521; Sb_Kenya/FJ897160; Sb_Tanzania/AY157212), 2 from $S$. guineensis (haplotype code/COI mtDNA accession No: Sg_Sao Tome and Principe/AJ519517 and Sg_Cameroon/ AJ519522), 1 from $S$. curassoni (haplotype code/COI mtDNA accession No: Sc_Senegal/AJ519516), and 1 from S. intercalatum (haplotype code/COI mtDNA accession No:

Table 3 The 11 profiles of the ITS rDNA region, and their positions, harbored by cow (BK, Kf, and $\mathrm{Kg}$ ) and schoolchild (DK and KE) in Kessounou Village, Benin

\begin{tabular}{|c|c|c|c|c|c|c|c|c|c|c|c|}
\hline \multirow[t]{2}{*}{ Species } & \multirow[t]{2}{*}{ Profile } & \multicolumn{3}{|c|}{ ITS1 } & \multirow{2}{*}{$\begin{array}{l}5.8 \\
556\end{array}$} & \multicolumn{4}{|c|}{ ITS2 } & \multirow[t]{2}{*}{ Host } & \multirow[t]{2}{*}{ Sample (Number of sequenced larval stages) } \\
\hline & & 41 & 73 & 257 & & 725 & 780 & 830 & 900 & & \\
\hline S. bovis & 1 & $\mathrm{~T}$ & $\mathrm{G}$ & $\mathrm{T}$ & $\mathrm{C}$ & A & $\mathrm{T}$ & A & $\mathrm{T}$ & Cow & $\begin{array}{l}\text { BK19(4); BK24(1); BK26(1); BK29(4); Kf5(5); } \\
\text { Kf6(3); Kf8(3); Kf9(3) }\end{array}$ \\
\hline S. haematobium & 2 & $\mathrm{~T}$ & A & $\mathrm{T}$ & $\mathrm{C}$ & $\mathrm{G}$ & $\mathrm{C}$ & $\mathrm{G}$ & $\mathrm{C}$ & Schoolchild & KE14 (urine(1) and stool(1)) \\
\hline \multirow{9}{*}{$\begin{array}{l}\text { S. bovis } x S \text {. } \\
\quad \text { haematobium }\end{array}$} & 3 & $\mathrm{~T}$ & G & $\mathrm{Y}$ & $\mathrm{C}$ & $\mathrm{A}$ & $\mathrm{T}$ & $\mathrm{A}$ & $\mathrm{T}$ & Cow & BK19(1); BK29(1) \\
\hline & 4 & $\mathrm{~T}$ & $\mathrm{R}$ & $\mathrm{T}$ & $\mathrm{C}$ & $\mathrm{A}$ & $\mathrm{T}$ & $\mathrm{A}$ & $\mathrm{T}$ & \multirow{5}{*}{ Schoolchild } & BK24(3); BK26(3) \\
\hline & 5 & $\mathrm{~T}$ & $\mathrm{~A}$ & $\mathrm{~T}$ & $\mathrm{Y}$ & G & $\mathrm{C}$ & G & $\mathrm{C}$ & & DK54(2); KE14 (urine(4) and stool(2)); KE15(2) \\
\hline & 6 & $\mathrm{~T}$ & A & $\mathrm{T}$ & $\mathrm{C}$ & $\mathrm{R}$ & $\mathrm{Y}$ & $\mathrm{R}$ & $\mathrm{Y}$ & & DK23(1); KE14 (stool(1)); KE15(1) \\
\hline & 7 & $\mathrm{Y}$ & $\mathrm{A}$ & $\mathrm{T}$ & $\mathrm{C}$ & G & $\mathrm{C}$ & G & $\mathrm{C}$ & & DK23(2); KE14 (urine(1) and stool(1)) \\
\hline & 8 & $\mathrm{Y}$ & $\mathrm{A}$ & $\mathrm{T}$ & $\mathrm{Y}$ & G & $\mathrm{C}$ & G & $\mathrm{C}$ & & DK23(1); KE14 (urine(4) and stool(4)); KE15(4) \\
\hline & 9 & $\mathrm{Y}$ & $\mathrm{A}$ & $\mathrm{T}$ & $\mathrm{C}$ & $\mathrm{R}$ & $\mathrm{Y}$ & $\mathrm{R}$ & $\mathrm{Y}$ & \multirow{3}{*}{$\begin{array}{l}\text { Cow and } \\
\text { Schoolchild }\end{array}$} & DK23(1); KE14 (stool(2)); KE15(2) \\
\hline & 10 & $\mathrm{~T}$ & A & $\mathrm{T}$ & $\mathrm{C}$ & A & $\mathrm{T}$ & A & $\mathrm{T}$ & & BK24(1); BK26(1); Kg1(5); KE14 (urine(2)) \\
\hline & 11 & $\mathrm{~T}$ & A & $\mathrm{T}$ & $\mathrm{Y}$ & $\mathrm{R}$ & Y & $\mathrm{R}$ & $\mathrm{Y}$ & & Kg2(5); DK23(1); KE14 (urine(2) and stool(2)); KE15(1) \\
\hline
\end{tabular}

$\mathrm{Y}$ indicates the presence of the bases $\mathrm{T}$ and $\mathrm{C}$, rather than an ambiguous reading between $\mathrm{T}$ and $\mathrm{C}$. Similarly, $\mathrm{R}$ indicates the presence of the bases $\mathrm{A}$ and $\mathrm{G}$ and not an ambiguous reading between $\mathrm{A}$ and $\mathrm{G}$ 
Si_Democratic Republic of the Congo/AJ519515) obtained at the GenBank database. Maximum likelihood tree topology of COI mtDNA showed that all 13 haplotypes which came from cows and schoolchildren belonged to the $S$. bovis clade and not to the S. haematobium or to other Schistosoma species clades (Fig. 4). The percentages of differences ranged between 0.23 and $1.70 \%$ between our 13 haplotypes and the $S$. bovis haplotypes from Senegal, Kenya, and Tanzania. We found $0 \%$ difference between K_Child_Hap11 and the haplotype from SôTchanhoué, Benin. We also found $0 \%$ difference between K_Child_Hap13 and the Corsica3 haplotype.

\section{Egg morphometry}

Two or three morphotypes were observed according to the host and the excreta (urine or feces/stool). In cow feces, three morphotypes were found: S. bovis, S. haematobium, and their intermediate morphotype (Fig. 5a-c); in schoolchild stool (Fig. 5d, e) and urine (Fig. 5f, g), two morphotypes were found: S. haematobium and an intermediate morphotype.

The percentages of each morphotype are presented in Fig. 6 for each origin. The percentage of $S$. bovis morphotype was high $(63.8 \%)$ in the cow feces, and null in schoolchild (stool and urine origins) $(p<0.05)$. The percentages of intermediate morphotype were not different between the origins $(p>0.05)$. The percentage of $S$. haematobium morphotype observed from cow feces origin was significantly lower than those from both stool and urine of schoolchild origins $(p<0.05)$. For each origin, the percentages of $S$. bovis, intermediate and S. haematobium morphotypes were all significantly different from each other $(p<0.05)$.
Fig. 4 Maximum likelihood tree topology built with the 13 haplotypes COI mtDNA (881 bp) showing that $S$. haematobium from Kessounou (recovered either from cows or schoolchildren) belongs to the $S$. bovis clade. Haplotype code/COI mtDNA accession No: K_Cow_Hap1/ MT159589, K_Cow_Hap2/ MT159590, K_Cow_Hap3/ MT159591, K_Cow_Hap4/ MT159592, K_Cow_Hap5/ MT159593, K_Cow_Hap6/ MT159594, K_Child_Hap7/ MT159595, K_Child_Hap8/ MT159596, K_Child_Hap9/ MT159597, K_Child_Hap10/ MT159598, K Child Hap11/ MT159599, K_Child_Hap12/ MT159600, K_Child_Hap13/ MT159601). The scale shows the number of nucleotide substitutions per site

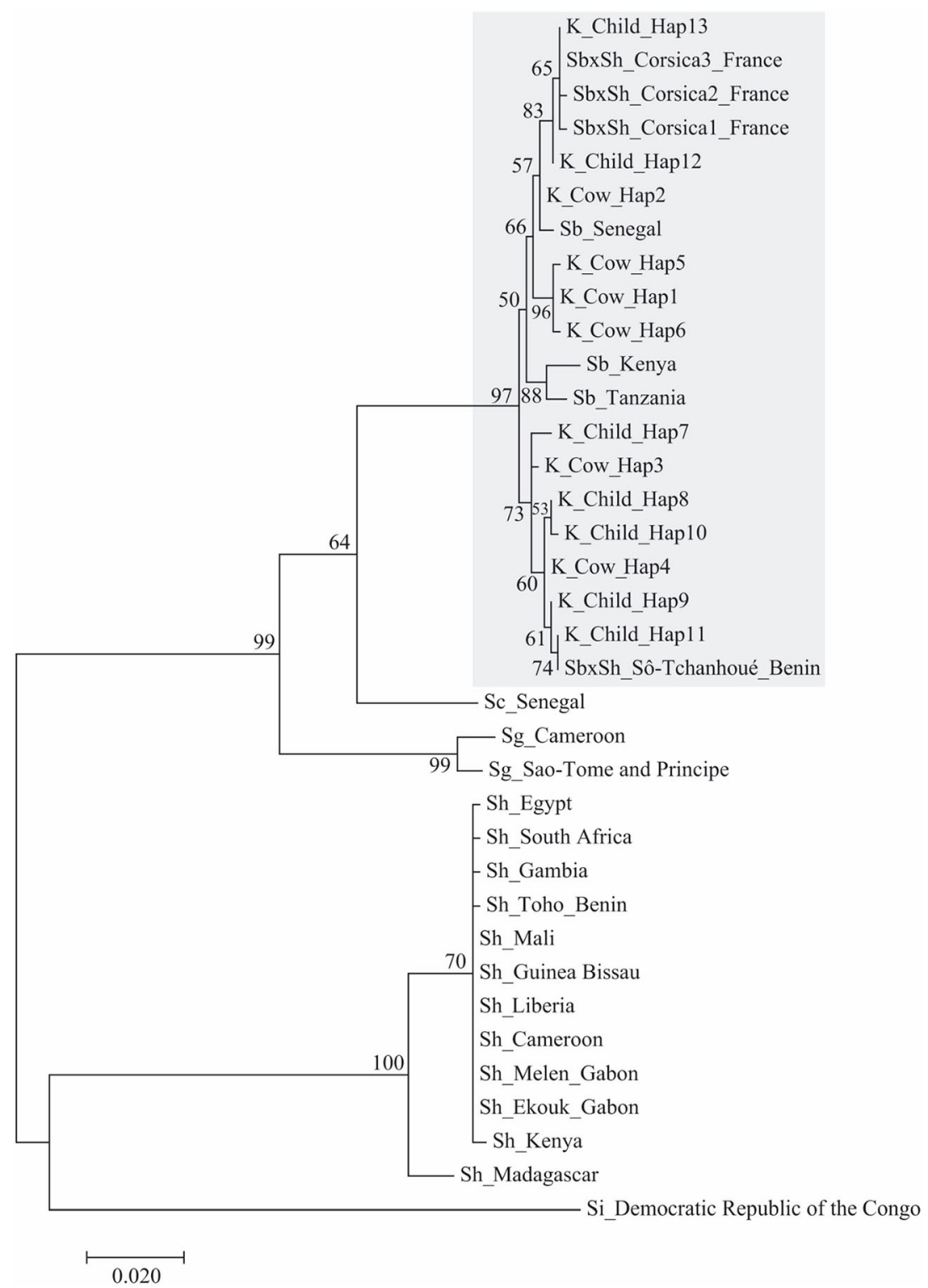




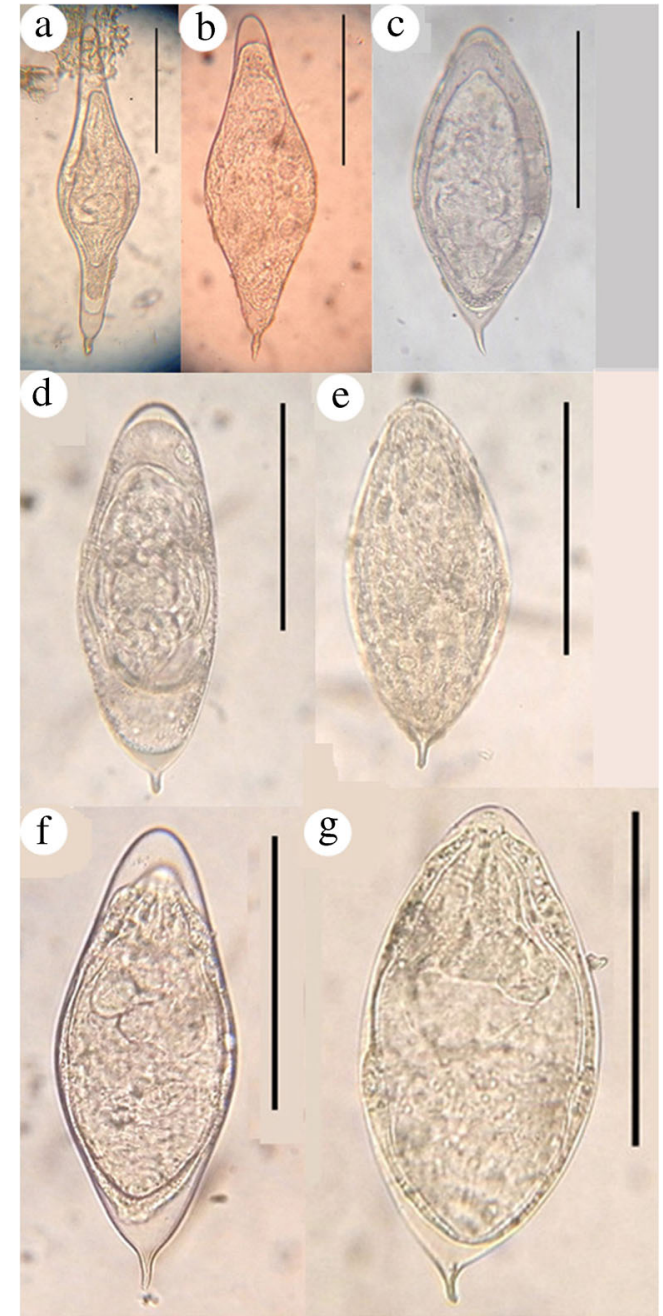

Fig. 5 Egg morphology. Cow feces, a $S$. bovis morphotype, b intermediate morphotype, c $S$. haematobium morphotype. Schoolchild stool, d intermediate morphotype, e $S$. haematobium morphotype. Schoolchild urine, f intermediate morphotype, g S. haematobium morphotype. Bar represents $100 \mu \mathrm{m}$
The morphometry of the eggs from cows and schoolchildren is presented in Table 4 and Fig. 7. For the S. bovis morphotype, no comparison could be made since this morphotype was not present in schoolchildren. For the intermediate morphotype, mean egg length and spine length were significantly higher for the cow feces origin $(p<0.05)$ and no difference was observed between the urine and the stool of the schoolchildren $(p>0.05)$. The mean length/width ratio was significantly smaller for the eggs obtained from schoolchild urine $(p<0.05)$ and no differences were observed between the schoolchild and cow feces $(p>0.05)$. For the $S$. haematobium morphotype, no major difference was observed between the origins $(p>0.05)$. The comparisons between morphotypes indicated that mean egg length and egg length/width ratio from urine or from stool were significantly higher in $S$. bovis morphotype compared to the intermediate one and higher in the intermediate morphotype compared to the $S$. haematobium one $(p<0.05)$. The plot of the egg width $(\mu \mathrm{m})$ and egg length $(\mu \mathrm{m})$ for schoolchild urine (green diamonds), schoolchild stool (blue squares), and cow feces (orange triangles) showed that the eggs from schoolchild urine and stool were grouped together but that those of cow feces constituted a separate group, with some individuals making the link between the two groups showing a higher variability in the eggs from cows compared to the eggs from schoolchildren.

\section{Discussion}

The results showed a chronobiological polymorphism in the cercarial emergence rhythm from snails exposed to miracidia collected from cow feces, with four different patterns.

The first pattern, early diurnal, exhibited a typical $S$. bovis cercarial emission; it was obtained in 7 B. forskalii among 11 (Kf1, Kf2, Kf3, Kf6, Kf7, Kf8, and Kf11). Such a pattern was found in $S$. bovis from Sardinia (Italy), Sudan and Spain
Fig. 6 Percentages of each egg morphotype (S. bovis, black; intermediate, dots;

S. haematobium, grey) according to origin (cow feces, schoolchild stool, schoolchild urine)

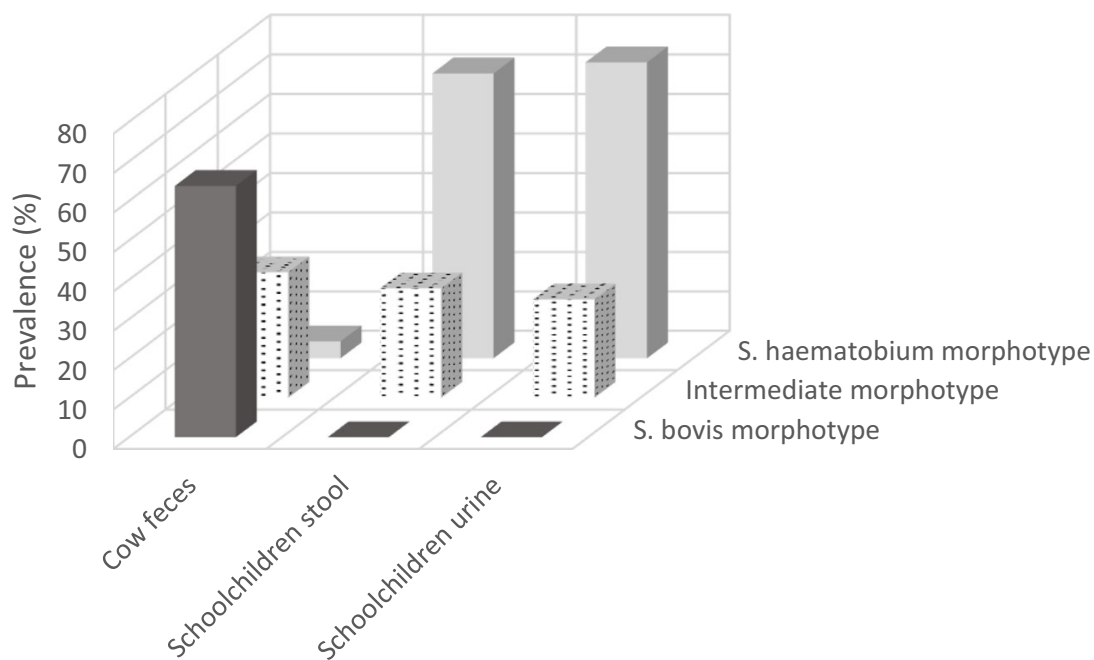


Table 4 Egg morphometry (mean $(\mu \mathrm{m}) \pm$ standard error)

\begin{tabular}{|c|c|c|c|c|c|c|c|c|c|}
\hline \multirow{2}{*}{$\begin{array}{l}\text { Morphotype } \\
\text { Origin }\end{array}$} & \multicolumn{3}{|l|}{ S. bovis } & \multicolumn{3}{|c|}{ Intermediate } & \multicolumn{3}{|c|}{ S. haematobium } \\
\hline & $\mathrm{CF}$ & SS & SU & $\mathrm{CF}$ & SS & SU & $\mathrm{CF}$ & SS & SU \\
\hline Length & $247.83^{\mathrm{b}}$ & na & na & $223.17^{\mathrm{a}, \mathrm{b}}$ & 153.00 & $148.54^{\mathrm{b}}$ & 140.00 & 138.85 & 132.01 \\
\hline SE & 4.03 & na & na & 7.51 & 5.48 & 3.82 & 42.43 & 4.68 & 1.66 \\
\hline $\mathrm{N}$ & 30.00 & na & na & 15.00 & 5.00 & 12.00 & 2.00 & 13.00 & 36.00 \\
\hline Min & 205.00 & na & na & 170.00 & 140.00 & 135.00 & 110.00 & 120.00 & 117.50 \\
\hline $\operatorname{Max}$ & 300.00 & na & na & 262.50 & 170.00 & 170.00 & 170.00 & 175.00 & 170.00 \\
\hline Width & $69.58^{\mathrm{b}}$ int & na & na & $83.17^{\mathrm{a}}$ & $56.00^{\mathrm{a}, \mathrm{b}}$ & $68.13^{\mathrm{a}}$ & 67.50 & 68.85 & 68.96 \\
\hline SE & 1.56 & na & na & 2.19 & 3.26 & 2.04 & 17.68 & 3.25 & 1.62 \\
\hline $\mathrm{N}$ & 30.00 & na & na & 15.00 & 5.00 & 12.00 & 2.00 & 13.00 & 36.00 \\
\hline Min & 57.50 & na & na & 65.00 & 50.00 & 60.00 & 55.00 & 50.00 & 50.00 \\
\hline $\operatorname{Max}$ & 90.00 & na & na & 100.00 & 65.00 & 80.00 & 80.00 & 95.00 & 85.00 \\
\hline Spine length & 17.38 & na & na & $17.31^{\mathrm{a}} \mathrm{SU}$ & 13.33 & 10.94 & 17.50 & $10.31^{\mathrm{a}}$ & 12.59 \\
\hline $\mathrm{SE}$ & 0.68 & na & na & 1.04 & 4.45 & 0.49 & 3.54 & 0.61 & 0.48 \\
\hline $\mathrm{N}$ & 20.00 & na & na & 13.00 & 3.00 & 8.00 & 2.00 & 8.00 & 29.00 \\
\hline Min & 12.50 & na & na & 10.00 & 7.50 & 10.00 & 15.00 & 7.50 & 10.00 \\
\hline Max & 22.50 & na & na & 22.50 & 20.00 & 12.50 & 20.00 & 12.50 & 20.00 \\
\hline Length/Width & $3.59^{\mathrm{b}}$ & na & na & $2.68^{\mathrm{b}}$ & $2.75^{\mathrm{b}}$ & $2.19^{\mathrm{a}, \mathrm{b}}$ & $2.06^{\mathrm{b}}$ & $2.04^{\mathrm{b}}$ & 1.94 \\
\hline $\mathrm{SE}$ & 0.07 & na & na & 0.05 & 0.11 & 0.07 & 0.09 & 0.07 & 0.04 \\
\hline $\mathrm{N}$ & 30.00 & na & na & 15.00 & 5.00 & 12.00 & 2.00 & 13.00 & 36.00 \\
\hline Min & 2.93 & na & na & 2.31 & 2.50 & 1.93 & 2.00 & 1.71 & 1.63 \\
\hline Max & 4.17 & na & na & 2.93 & 3.10 & 2.72 & 2.13 & 2.50 & 2.60 \\
\hline
\end{tabular}

$C F$ cow feces, $S S$ schoolchild stool, $S U$ schoolchild urine, $S E$ standard error, $N$ number of eggs

${ }^{a}$ Mann-Whitney test: significantly different from the other origins of the same morphotype

${ }^{\mathrm{b}}$ Mann-Whitney test: significantly different from the other morphotypes of the same origin
(Mouahid et al. 1987, 1991), and Niger (Mouchet et al. 1992). The COI mtDNA molecular analyses, conducted on cercariae from 2 snails among the 7 (Kf6 and Kf8), showed that the DNA sequences (K Cow Hap2) belonged to the $S$. bovis clade. Schistosoma bovis has an extensive geographical distribution (Moné et al. 1999), and in their review, Moné et al. showed that this species was naturally found in all of the neighboring countries of Benin: Togo, Burkina Faso, Niger, and Nigeria. However, while this is the first time that this species has been found naturally in Benin, this result is not surprising. Furthermore, if the presence of $S$. bovis was not surprising in cows, the presence of COI mtDNA $S$. bovis haplotypes in all of the schoolchildren samples confirms that introgressive hybridization between $S$. bovis and $S$. haematobium exists in humans in
Fig. 7 Plot of the egg width $(\mu \mathrm{m})$ and egg length $(\mu \mathrm{m})$ for schoolchild urine (diamonds), schoolchild stool (squares) and cow feces (triangles)

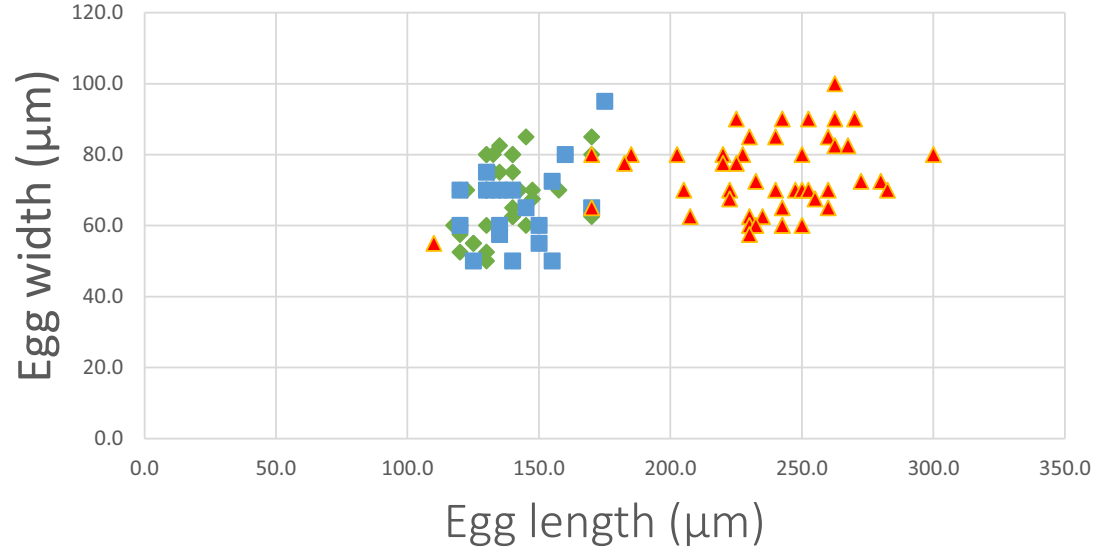

- Schoolchild urine $\quad$ Schoolchild stool $\Delta$ Cow feces 
Benin, as shown previously by Moné et al. (2015). The phylogenetic analysis showed that 2 of the 6 haplotypes recovered from cows (K_Cow_Hap3 and K_Cow_Hap4) and 5 of the 7 haplotypes recovered from schoolchildren (K_Child_Hap7, K_Child_Hap8, K_Child_Hap9, K_Child_Hap10, and K Child Hap11) grouped with the one from Sô-Tchanhoué from Benin, confirms previous results on introgressive hybridization between $S$. bovis and $S$. haematobium with respect to humans in this area (Moné et al. 2015). The four last haplotypes recovered from cows (K_Cow_Hap1, K_Cow_Hap2, K_Cow_Hap5, and K_Cow_Hap6) grouped with the S. bovis haplotypes. The last two haplotypes recovered in humans (K_Child_Hap12 and K_Child_Hap13) grouped with those from Corsica, with the haplotype number 13 being exactly the same as the Corsica 3 haplotype. This result provides insight into the origin of the Corsican hybrids which was previously attributed to Senegal (Boissier et al. 2016) on the basis of 407 positions. The phylogenetic tree in the present work, based on 881 positions of the COI mtDNA, showed that the origin of Corsican haplotypes could be attributed to Benin.

The second pattern, midday to late diurnal, was new for cercarial emission in cows while it was similar to what has been published on S. haematobium in humans from Algeria (Kéchemir and Théron 1997), Morocco (Mouahid et al. 1991), Niger (Pagès and Théron 1990; Mouchet et al. 1992), and Gabon (Mintsa-Nguema et al. 2014). This is the first time that a typical $S$. haematobium pattern has been observed in cows as $S$. haematobium has always been thought to have the highest specificity to humans. This atypical pattern from cows was not due to the fact that the cercariae were shed by B. globosus $(\mathrm{Kg} 2)$ since it has been shown that the taxa of the snail from which the cercariae emerge does not determine the cercarial emergence pattern of S. bovis (Mouahid and Théron 1986). Furthermore, hybridization in schistosomes is known to be accompanied by heterosis (hybrid vigor), including the capability of hybrid schistosomes to open their snail intermediate host spectrum (Wright and Ross 1980; Webster and Southgate 2003; Huyse et al. 2009). Bulinus forskalii is the main snail host for $S$. bovis in Sub-Saharian Africa while B. globosus is the main snail host for $S$. haematobium in this area (Brown 1994). The fact that a B. globosus was shedding this atypical pattern could stem from the opening of the snail host spectrum by this $S$. bovis $x$ S. haematobium new pattern. The molecular and phylogenetic results presented in this paper support this idea since this $S$. bovis COI mtDNA haplotype (K_Cow_Hap4) grouped with the one from Sô-Tchanhoué from Benin harboring a $S$. haematobium x S. bovis genetic pattern (Moné et al. 2015). The molecular analyses also showed an atypical ITS rDNA profile for this sample (profile 11), with a $S$. haematobium pattern for ITS1 and double peaks for both 5.8S and ITS2 (Table 3). These results show that in this area, introgressive hybridization exists between $S$. bovis and $S$. haematobium in cows as well. This is the first time that such an introgressive hybridization has been identified in domestic bovines. Previous results showed introgression between $S$. bovis and $S$. haematobium in humans (Brémond et al. 1993; Huyse et al. 2009; Webster et al. 2013; Moné et al. 2015; Leger et al. 2016; Soentjens et al. 2016; Angora et al. 2019) and rodents (Catalano et al. 2018).

The third pattern corresponded to a new pattern for $S$. bovis, with both a typical early pattern for $S$. bovis accompanied by a nocturnal emergence peak at $7 \mathrm{pm}$. This pattern was obtained from 4 of the 11 B. forskalii snails (Kf4, Kf5, $\mathrm{Kf9}$, and $\mathrm{Kf10}$ ). This is the first time that a double peak in cercarial emergence is shown for $S$. bovis. Another animal schistosome, S. margrebowiei Le Roux, 1933 also showed two emergence peaks per day, with the first peak occurring $1 \mathrm{~h}$ after the onset of daylight, and the second peak $1 \mathrm{~h}$ after the onset of darkness (Raymond and Probert 1991). This is also the first time that a nocturnal cercarial emergence is shown for S. bovis. In another species of schistosome, S. mansoni, atypical chronotypes were found with nocturnal shedding. A three-peak cercarial emergence was found in southern Benin in both natural and experimental infections, with one peak in the early morning, a second around midday, and a third one at the beginning of the night (Ibikounle et al. 2012). Another chronotype that displayed a strictly nocturnal emergence was shown in Oman and was related to the presence of reservoir hosts (rodents) in the transmission sites (Mouahid et al. 2012). However, this particular S. mansoni nocturnal chronotype was purely nocturnal and was not accompanied by diurnal cercarial emergence from the same individual snail. Several hypotheses could be proposed for the two peaks in diurnal-nocturnal cercarial emergence. First, the peaks may coincide with the behavior of the definitive host where cattle would go twice a day to drink and S. bovis would thus be adapted to this behavior. This explanation could also apply in the case of $S$. margrebowiei. Second, the peaks may be due to the presence of nocturnal reservoir hosts for $S$. bovis, like rodents, with nocturnal watering behaviors. This explanation would apply in the case of $S$. mansoni from Oman (Mouahid et al. 2012). Lastly, the peaks may have resulted in response to the presence of introgressive hybridization between $S$. bovis and a nocturnal population of $S$. bovis or another species of schistosome. It is difficult, however, to get a nocturnal pattern with two diurnal species of schistosomes (in our case, $S$. bovis and S. haematobium), even if they can hybridize. Pagès and Théron (1990) conducted crossing experiments between $S$. bovis from Spain and S. haematobium from Niger and the F1 hybrids harbored the same chronobiological pattern as the parental $S$. bovis, i.e., with an early peak. Unfortunately, these authors did not analyze the F2 generations. Furthermore, double infections were experimentally done with both $S$. bovis from Sardinia (Italy) and S. haematobium from Morocco and both species kept their own cercarial shedding rhythm in the doubly infected snails (Mouahid et al. 1991). This was also 
the case for $S$. mansoni with both early and late diurnal patterns (Théron et al. 1997). The cercariae from 2 of the 4 snails (Kf5 and Kf9) used for cercarial emergence pattern were analyzed for molecular biology and showed $S$. bovis COI mtDNA haplotypes (K_Cow_Hap1 and K_Cow_Hap2). Both COI mtDNA haplotypes were found from different cercariae found in a single snail sample suggesting that, perhaps, 2 miracidia succeeded in developing in this one snail, leading to the double peak in cercarial emergence. However, as the other snail sample had only 1 COI mtDNA haplotype (K_Cow_Hap2) and yielded the same double peak pattern, this hypothesis is unsupported. The phylogenetic analysis showed that these COI mtDNA haplotypes (K_Cow_Hap1 and K_Cow_Hap2) grouped with the $S$. bovis haplotypes from other countries. The molecular analyses also showed typical ITS rDNA $S$. bovis profiles for these samples (profile 1).

The fourth chronotype, obtained from one B. globosus snail (Kg1), corresponded to a new chronotype for $S$. bovis, with both a typical $S$. haematobium late diurnal pattern accompanied by a nocturnal emergence peak at $7 \mathrm{pm}$. This is the first time that a midday to late diurnal peak together with a nocturnal peak was identified in $S$. bovis. This result shares similarities with the pattern with the previous one, with the presence of nocturnal cercarial shedding, but is different in that the early pattern in $S$. bovis was replaced by a late $S$. haematobium pattern. The molecular studies showed that this sample had the same COI mtDNA haplotype (K_Cow_Hap4) as the one linked to the second cercarial emergence pattern (S. haematobium midday to late diurnal pattern) and the phylogenetic analyses grouped this haplotype with the one from Sô-Tchanhoué, Benin. Furthermore, the ITS rDNA profile of all the cercariae in this sample (profile 10) showed a typical $S$. haematobium ITS1 marker together with a typical $S$. bovis ITS2 marker. Further studies on the behavior of the cattle and the presence of rodents as reservoir hosts are needed to explain this atypical pattern of cercarial emergence.

The results showed a polymorphism in egg morphology in both cows and schoolchildren, with 3 morphotypes. The first, the $S$. bovis morphotype, represented over $60 \%$ of the eggs in cow feces and no $S$. bovis morphotype was found in either the stool or urine of schoolchildren. Still, this result shows that $40 \%$ of the eggs recovered in the cows did not have a S. bovis morphotype and leads us to also suspect hybridization in cows between $S$. bovis and $S$. haematobium. With respect to egg morphometry, mean egg length of our $S$. bovis morphotype $(247 \mu \mathrm{m})$ was similar to those recorded for $S$. bovis from cow feces (from 179 to $260 \mu \mathrm{m}$ (Alves (1949); Pitchford (1965)). The second morphotype, S. haematobium, represented around $4 \%$ of the eggs in cow feces, compared to over $70 \%$ of the eggs in both stool and urine of the schoolchildren. This result showed that some eggs which harbored the S. haematobium morphotype were present in cows and that $30 \%$ of the eggs recovered in the schoolchildren lacked a $S$. haematobium morphotype, leading us to also suspect hybridization between $S$. bovis and S. haematobium in both cows and humans. Mean egg lengths of our $S$. haematobium morphotypes (132 to $140 \mu \mathrm{m}$ ) were similar to those recorded for $S$. haematobium eggs (from 131 to $146 \mu \mathrm{m}$; see Pitchford (1965), Loker (1983), Richard-Lenoble et al. (1993), and Moné et al. (2012)). The third chronotype, an intermediate morphotype between $S$. bovis and $S$. haematobium, sustained the hybridization between $S$. bovis and $S$. haematobium, as we would have suspected from the cercarial emergence results. Even if the shape of the eggs produced is not necessarily a guide to the genetic constitution of the enclosed larvae, as stated by Wright and Ross (1980), these authors also suspected natural hybrids between $S$. haematobium and $S$. mattheei thanks to $S$. mattheei-like eggs in a human infection. Mean egg lengths for our intermediate morphotypes, between $S$. bovis and S. haematobium (148 to $223 \mu \mathrm{m}$ ), also suggest the presence of hybridization between these two species in both cows and humans. However, much smaller intermediate egg sizes were found in the hybrids we found between $S$. bovis and S. haematobium in Corsica, France (Moné et al. 2015). A higher variability in the morphometry of the eggs was observed in cow feces compared to schoolchild stool or urine and thus place the cow host as the host which provides the largest panel of eggs for schistosome transmission in the area.

In conclusion, our results showed, for the first time, (i) the presence of $S$. bovis in Benin, (ii) the presence of introgressive hybridization between $S$. bovis and S. haematobium in domestic cattle, and (iii) the presence of atypical chronobiological patterns in schistosomes from cattle, with typical S. haematobium shedding pattern, double-peak patterns and nocturnal patterns. They also confirmed that introgressive hybridization between $S$. bovis and $S$. haematobium exists in humans in Benin. Very little comparison is possible between the present findings and the literature, because until now, the researchers who worked on introgressive hybridization had never analyzed the cercarial emergence patterns from naturally-infected cows. Our results showed that the chronobiological life-history trait is useful for the detection of new hosts and also may reveal the possible presence of introgressive hybridization in schistosomes. They also showed that another life-history trait, the prepatent period, which is known to be short for Schistosoma bovis (21-22 days, Mouahid and Théron 1987) and long for Schistosoma haematobium (32 to 43 days, Ibikounlé et al. 2013) was intermediate for all our samples (26 to 32 days).

Our results, for the first time, place cattle as reservoir host for $S$. haematobium and S. bovis $x$ S. haematobium. The proximity between humans and cattle in Kessounou, like in many villages in Africa, is favorable for the interactions between their schistosomes, S. haematobium for humans and S. bovis for cattle. The consequences of these results on the epidemiology of the disease, the transmission to humans, and the control of the disease 
are very important. They show that the definitive host spectrum of $S$. haematobium may be opened to include cattle; further research should be done regarding the importance of rodents, especially in nocturnal schistosomiasis.

Our results are not congruent with two recently published papers which suggest that hybridization may occur quite infrequently between $S$. bovis and $S$. haematobium. Boon et al. (2019) found strong differentiation between $S$. bovis and $S$. haematobium in human populations of the Senegal River Basin, suggesting that there is minimal gene flow between them. However, in their paper, they found a miracidium harboring a double $S$. bovis and S. haematobium ITS rDNA profile from a neighborhood village which was genetically highly differentiated from the others. They also questioned about the previous findings by Huyse et al. (2009) and Webster et al. (2013) showing the existence of contemporary hybrid crosses between $S$. bovis and $S$. haematobium in humans in Senegal. Platt et al. (2019) studied the exomes of miracidia coming from humans in Niger and Zanzibar and their data did not reveal any evidence for contemporary hybridization. Instead, they showed ancient introgression of some $S$. bovis alleles into the genome of $S$. haematobium in Niger. We are aware that our data were genotyped with just two loci (COI mtDNA and ITS rDNA) and that they may provide little power to detect recent hybridization. However, unlike other recent results, our data showed that double $S$. bovis and $S$. haematobium ITS rDNA profiles were not rare in Kessounou village suggesting a recent hybridization, as the ITS rDNA marker can retain both parental copies for several generations before they are homogenized by concerted evolution (Sang et al. 1995). Our results show that, in some places in Benin, gene flow between $S$. bovis and $S$. haematobium is present.

Acknowledgments We would like to thank M. Marius CODJO, chief of Kessounou village and all the breeders and also M. Jean-Pierre TOKPO, Director of Kessounou school and all the schoolchildren for their participation to the study.

Authors' contributions Conceptualization: Hélène Moné, Gabriel Mouahid, Moudachirou Ibikounlé.

Material preparation, data collection and analysis: Boris A.E.S. Savassi, Gabriel Mouahid, Chrystelle Lasica, Samoussou-Dine K. Mahaman, Jean-François Allienne, Moudachirou Ibikounlé, Hélène Moné.

Funding acquisition: Gabriel Mouahid, André Garcia, David Courtin, Moudachirou Ibikounlé, Hélène Moné

Investigation: Boris A.E.S. Savassi, Gabriel Mouahid, Chrystelle Lasica, Samoussou-Dine K. Mahaman, Jean-François Allienne, Moudachirou Ibikounlé, Hélène Moné.

Methodology: Hélène Moné, Gabriel Mouahid, Moudachirou Ibikounlé.

Project administration: Gabriel Mouahid, André Garcia, David Courtin, Moudachirou Ibikounlé, Hélène Moné.

Resources: Boris A.E.S. Savassi, Gabriel Mouahid, Chrystelle Lasica, Samoussou-Dine K. Mahaman, André Garcia, David Courtin, JeanFrançois Allienne, Moudachirou Ibikounlé, Hélène Moné.

Supervision: Gabriel Mouahid, Hélène Moné.
Validation: Gabriel Mouahid, Hélène Moné

Visualization: Gabriel Mouahid, Hélène Moné.

Writing-original draft: Boris A.E.S. Savassi, Gabriel Mouahid, Hélène Moné.

Writing-review \& editing: Boris A.E.S. Savassi, Gabriel Mouahid, Chrystelle Lasica, André Garcia, David Courtin, Jean-François Allienne, Moudachirou Ibikounlé, Hélène Moné.

All authors read and approved the final manuscript.

Funding information This research was funded by the French Ministry of Foreign Affairs, the "Laboratoire Mixte International" (Mixed International Laboratory) on the project CONS-HELM « Infections helminthiques: traitements et conséquences sur la santé et le développement au Sud », and the French National Agency for Research (ANR) [grant ANR-17-CE12-0005-01] CHRONOGET and CNRS. BS is a student fellow from the SCAC (Service de Coopération et d'Action Culturelle), French Embassy in Benin; CL is a student fellow from the Occitanie Region, France.

\section{Compliance with ethical standards}

Conflict of interest The authors declare that they have no conflict of interest.

Ethical approval Ethical permission (No119, 17/07/2019/CER-ISBA) was obtained from the Ethic Committee of the «Institut des Sciences Biomédicales Appliquées, Faculté de Médecine, Université d'AbomeyCalavi, 01BP526, Cotonou, Benin.

Informed consent The Director of Kessounou school obtained informed consent from the parents of all the schoolchildren who participated to the study.

Data set availability Sequence data were deposited in the NCBI GenBank database under the accession numbers MT159589 to MT159601 for COI mtDNA and MT158872 to MT158882 for ITS rDNA.

\section{References}

Abou M, Yabi I, Yolou I, Ogouwale E (2018) Caractérisation des systèmes de production sur les sites d'aménagements hydroagricoles dans le doublet Dangbo-Adjohoun au sud du Bénin. Int J Biol Chem Sci 12:462-478

Alves W (1949) The eggs of Schistosoma bovis, S. mattheei and S. haematobium. J Helminthol 23:127-134

Angora EK, Allienne J-F, Rey O, Menan H, Touré AO, Coulibaly JT, Raso G, Yavo W, N'Goran EK, Utzinger J, Balmer O, Boissier J (2019) High prevalence of Schistosoma haematobium $\times$ Schistosoma bovis hybrids in schoolchildren in Côte d'Ivoire. Parasitology 147:287-294

Barber K, Mkoji G, Loker E (2000) PCR-RFLP analysis of the ITS2 region to identify Schistosoma haematobium and S. bovis from Kenya. Am J Trop Med Hyg 62:434-440

Beltran S, Galinier R, Allienne J-F, Boissier J (2008) Cheap, rapid and efficient DNA extraction method to perform multilocus microsatellite genotyping on all Schistosoma mansoni stages. Mem Inst Oswaldo Cruz 103:501-503

Boissier J, Grech-Angelini S, Webster BL, Allienne J-F, Huyse T, MasComa S, Toulza E, Barré-Cardi H, Rollinson D, Kincaid-Smith J, Oleaga A, Galinier R, Foata J, Rognon A, Berry A, Mouahid G, Henneron R, Moné H, Noel H, Mitta G (2016) Outbreak of 
urogenital schistosomiasis in Corsica (France): an epidemiological case study. Lancet Infect Dis. https://doi.org/10.1016/S14733099(16)00175-4

Boko PM, Ibikounlé M, Onzo-Aboki A, Tougoue J-J, Sissinto Y, Batcho W, Kindé-Gazard D, Kabore A (2016) Schistosomiasis and soil transmitted helminths distribution in Benin : a baseline prevalence survey in 30 districts. PLoS One 11:e0162798

Boon NAM, Mbow M, Paredis L, Moris P, Sy I, Maes T, Webster BL, Sacko M, Volckaert FAM, Polman K, Huyse T (2019) No barrier breakdown between human and cattle schistosome species in the Senegal River Basin in the face of hybridisation. Int J Parasitol 49: 1039-1048

Brémond P, Sellin B, Sellin E, Naméoua B, Labbo R, Théron A, Combes C (1993) Arguments for the modification of the genome (introgression) of the human parasite Schistosoma haematobium by genes from $S$. bovis, in Niger. C R Acad Sci Série III, Sciences de la vie 316:667-670

Brown DS (1994) Freshwater snails of Africa and their medical importance, revised 2nd edition. Taylor \& Francis Ltd, London, pp 608

Castresana J (2000) Selection of conserved blocks from multiple alignments for their use in phylogenetic analysis. Mol Biol Evol 17:540 552

Catalano S, Sene M, Diouf ND, Fall CB, Borlase A, Leger E, Ba K, Webster JP (2018) Rodents as natural hosts of zoonotic Schistosoma species and hybrids: an epidemiological and evolutionary perspective from West Africa. J Infect Dis 218:429-433

Chitsulo L, Engels D, Montresor A, Savioli L (2000) The global status of schistosomiasis and its control. Acta Trop 77:41-51

De Bont J, Vercruysse J (1997) The epidemiology and control of cattle schistosomiasis. Parasitol Today 13:255-262

De Bont J, Vercruysse J (1998) Schistosomiasis in cattle. Adv Parasitol 41:285-364

Dereeper A, Audic S, Claverie JM, Blanc G (2010) BLAST-EXPLORER helps you building datasets for phylogenetic analysis. BMC Evol Biol 10:8. https://doi.org/10.1186/1471-2148-10-8

Dereeper A, Guignon V, Blanc G, Audic S, Buffet S, Chevenet F, Dufayard JF, Guindon S, Lefort V, Lescot M, Claverie JM, Gascuel O (2008) Phylogeny.fr: robust phylogenetic analysis for the non-specialist. Nucleic Acids Res 36(Web Server issue): W465-W469. https://doi.org/10.1093/nar/gkn180

Edgar RC (2004) MUSCLE: multiple sequence alignment with high accuracy and high throughput. Nucleic Acids Res 32:1792-1797

Engels D, Chitsulo L, Montresor A, Savioli L (2002) The global epidemiological situation of schistosomiasis and new approaches to control and research. Acta Trop 82:139-146

Huyse T, Webster BL, Geldof S, Stothard R, Diaw OT, Polman K, Rollinson D (2009) Bidirectional introgressive hybridization between a cattle and human schistosome species. PLoS Pathog 5(9): e1000571

Ibikounlé M, Moné H, Abou Y, Kinde-Gazard D, Sakiti NG, Mouahid G, Massougbodji A (2012) Premier cas de chronobiologie des émissions cercariennes de type infradien chez Schistosoma mansoni dans deux foyers du sud-Bénin. Int J Biol Chem Sci 6:1081-1089

Ibikounlé M, Mouahid G, Mintsa-Nguema R, Sakiti N, Massougbodji A, Moné H (2013) Snail intermediate host/Schistosoma haematobium relationships from three transmission sites in Benin (West Africa). Parasitol Res 112:227-233

Kéchemir N, Théron A (1997) Intraspecific variation in Schistosoma haematobium from Algeria. J Helminthol 71:29-33

Kumar S, Stecher G, Tamura K (2016) MEGA7: molecular evolutionary genetics analysis version 7.0. Mol Biol Evol 33:1870-1874

Leger E, Garba A, Hamidou AA, Webster BL, Pennance T, Rollinson D, Webster JP (2016) Introgressed animal schistosomes Schistosoma curassoni and $S$. bovis naturally infecting humans. EID 22:2212

Lockyer A, Olson P, Østergaard P, Rollinson D, Johnston D, Attwood S, Southgate V, Horak P, Snyder S, Le T (2003) The phylogeny of the
Schistosomatidae based on three genes with emphasis on the interrelationships of Schistosoma Weinland, 1858. Parasitology 126: 203-224

Loker ES (1983) A comparative study of the life-histories of mammalian schistosomes. Parasitology 87:343-369

Mintsa-Nguema R, Moné H, Ibikounlé M, Mengué-Ngou-Milama K, Kombila M, Mouahid G (2014) Cercarial emergence pattern of Schistosoma haematobium from Libreville, Gabon. Parasite 21:3. https://doi.org/10.1051/parasite/2014004

Moné H, Holtfreter MC, Allienne J-F, Mintsa-Nguema R, Ibikounlé M, Boissier J, Berry A, Mitta G, Richter J, Mouahid G (2015) Introgressive hybridizations of Schistosoma haematobium by Schistosoma bovis at the origin of the first case report of schistosomiasis in Corsica (France, Europe). Parasitol Res 114:4127-4133

Moné H, Ibikounlé M, Massougbodji A, Mouahid G (2010) Human schistosomiasis in the Economic Community of West African States; epidemiology and control. Adv Parasitol 71:33-91

Moné H, Minguez S, Ibikounlé M, Allienne J-F, Massougbodji A, Mouahid G (2012) Natural interactions between S. haematobium and S. guineensis in the Republic of Benin. Sci World J 2012: 793420

Moné H, Mouahid G, Morand S (1999) The distribution of Schistosoma bovis Sonsino, 1876 in relation to intermediate host mollusc-parasite relationships. Adv Parasitol 44:99-138

Mouahid A, Théron A (1986) Schistosoma bovis: patterns of cercarial emergence from snails of the genera Bulinus and Planorbarius. Exp Parasitol 62:389-393

Mouahid A, Théron A (1987) Schistosoma bovis: variability of cercarial production as related to the snail hosts: Bulinus truncatus, $B$. wrighti and Planorbarius metidjensis. Int J Parasitol 17:1431-1434

Mouahid G, Idris MA, Verneau O, Théron A, Shaban MM, Moné H (2012) A new chronotype of Schistosoma mansoni: adaptive significance. Tropical Med Int Health 17:727-732

Mouahid A, Moné H, Arru E, Chassé J-L, Théron A, Combes C (1987) Analyse comparative du rythme d'émission des cercaires de trois souches de Schistosoma bovis. Parassitologia 29:79-85

Mouahid A, Moné H, Chaïb A, Théron A (1991) Cercarial shedding patterns of Schistosoma bovis and Schistosoma haematobium from single and mixed infections of Bulinus truncatus. J Helminthol 65: $8-14$

Mouchet F, Théron A, Brémond P, Sellin E, Sellin B (1992) Pattern of cercarial emergence of Schistosoma curassoni from Niger and comparison with three sympatric species of schistosomes. J Parasitol 78: 61-63

Nei M, Kumar S (2000) Molecular evolution and phylogenetics. Oxford University Press, New York

Onzo-Aboki A, Ibikounlé M, Boko PM, Savassi BS, Doritchamou J, Siko EJ, Daré A, Batcho W, Massougbodji A, Tougoue JJ (2019) Human Schistosomiasis in Benin: countrywide evidence of Schistosoma haematobium predominance. Acta Trop 191:185-197

Pagès J, Théron A (1990) Analysis and comparison of cercarial emergence rhythms of Schistosoma haematobium, S. intercalatum, S. bovis, and their hybrid progeny. Int J Parasitol 20:193-197

Pitchford R (1965) Differences in the egg morphology and certain biological characteristics of some African and Middle Eastern schistosomes, genus Schistosoma, with terminal-spined eggs. Bull World Health Organ 32:105-120

Platt RN, McDew-White M, Le Clec'h W, Chevalier F, Allan F, Emery AM, Garba A, Hamidou AA, Ame SM, Webster JP, Rollinson D, Webster BL, Anderson TJC (2019) Ancient hybridization and adaptive introgression of an invadolysin gene in schistosome parasites. Mol Biol Evol 36:2127-2142

Raymond K, Probert AJ (1991) The daily cercarial emission rhythm of Schistosoma margrebowiei with particular reference to dark period stimuli. J Helminthol 65:159-168 
Richard-Lenoble D, Kombila M, Duong TH, Gendrel D (1993) Schistosoma intercalatum schistosomiasis. A recent and forgotten schistosomiasis. Rev Praticien 43:432-439

Sang T, Crawford DJ, Stuessy TF (1995) Documentation of reticulate evolution in peonies (Paeonia) using internal transcribed spacer sequences of nuclear ribosomal DNA: implications for biogeography and concerted evolution. Proc Natl Acad Sci U S A 92:68136817

Soentjens P, Cnops L, Huyse T, Yansouni C, De Vos D, Bottieau E, Clerinx J, Van Esbroeck M (2016) Diagnosis and clinical management of Schistosoma haematobium-Schistosoma bovis hybrid infection in a cluster of travelers returning from Mali. Clin Infect Dis 63: 1626-1629

Théron A, Combes C (1988) Genetic analysis of cercarial emergence rhythms of Schistosoma mansoni. Behavior Gen 18:201-209

Théron A, Mouahid G, Moné H (1997) Schistosoma mansoni : cercarial shedding patterns from a mixed infection of Biomphalaria glabrata with two (early and late) chronobiological variants. Parasitol Res 83: 356-358

Van den Broeck F, Geldof S, Polman K, Volckaert F, Huyse T (2011) Optimal sample storage and extraction procotols for reliable multilocus genotyping of the human parasite Schistosoma mansoni. Infect Genet Evol 11:1413-1418

Webster BL, Southgate VR (2003) Compatibility of Schistosoma haematobium, S. intercalatum and their hybrids with Bulinus truncatus and B. forskalii. Parasitology 127:231-242

Webster BL, Diaw OT, Seye MM, Webster JP, Rollinson D (2013) Introgressive hybridization of Schistosoma haematobium group species in Senegal: species barrier breakdown between ruminant and human schistosomes. PLoS Negl Trop Dis 7(4):e2110. https://doi. org/10.1371/journal.pntd.0002110

Webster BL, Rollinson D, Stothard JR, Huyse T (2010) Rapid diagnostic multiplex PCR (RD-PCR) to discriminate Schistosoma haematobium and S. bovis. J Helminthol 84(107):114

World Health Organization (2019) Schistosomiasis. Fact sheet 17 April 2019

Wright C, Ross G (1980) Hybrids between Schistosoma haematobium and $S$. mattheei and their identification by isoelectric focusing of enzymes. Trans R Soc Trop Med Hyg 74:326-332

Publisher's note Springer Nature remains neutral with regard to jurisdictional claims in published maps and institutional affiliations. 